\title{
Article \\ Pharmacokinetics of Single Domain Antibodies and Conjugated Nanoparticles Using a Hybrid near Infrared Method
}

\author{
Shiran Su ${ }^{1,2}$, Thomas J. Esparza ${ }^{1,3}{ }^{1}$, Duong Nguyen ${ }^{1}$, Simone Mastrogiacomo ${ }^{1}$, Joong H. Kim ${ }^{1,3}$ \\ and David L. Brody $1,2,3,4, *$
}

1 Laboratory of Functional and Molecular Imaging, National Institute of Neurological Disorders and Stroke, National Institutes of Health, Bethesda, MD 20892, USA; shiran.su@nih.gov (S.S.); thomas.esparza@nih.gov (T.J.E.); dtn0028@gmail.com (D.N.); simone.mastrogiacomo@nih.gov (S.M.); caleb.kim@nih.gov (J.H.K.)

2 Department of Biomedical Engineering, Washington University in St. Louis, St. Louis, MI 63130, USA

3 Center for Neuroscience and Regenerative Medicine, Henry M. Jackson Foundation for the Advancement of Military Medicine, Bethesda, MD 20892, USA

4 Department of Neurology, Uniformed Services University of the Health Sciences, Bethesda, MD 20814, USA

* Correspondence: david.brody@nih.gov or david.brody@usuhs.edu

Citation: Su, S.; Esparza, T.J.;

Nguyen, D.; Mastrogiacomo, S.; Kim,

J.H.; Brody, D.L. Pharmacokinetics of Single Domain Antibodies and Conjugated Nanoparticles Using a Hybrid near Infrared Method. Int. J. Mol. Sci. 2021, 22, 8695. https:// doi.org/10.3390/ijms22168695

Academic Editor: Manuela Malatesta

Received: 29 June 2021

Accepted: 9 August 2021

Published: 13 August 2021

Publisher's Note: MDPI stays neutral with regard to jurisdictional claims in published maps and institutional affiliations.

Copyright: (c) 2021 by the authors. Licensee MDPI, Basel, Switzerland. This article is an open access article distributed under the terms and conditions of the Creative Commons Attribution (CC BY) license (https:/ / creativecommons.org/licenses/by/ $4.0 /)$.

\begin{abstract}
Iron oxide nanoparticles and single domain antibodies from camelids (VHHs) have been increasingly recognized for their potential uses for medical diagnosis and treatment. However, there have been relatively few detailed characterizations of their pharmacokinetics (PK). The aim of this study was to develop imaging methods and pharmacokinetic models to aid the future development of a novel family of brain MRI molecular contrast agents. An efficient near-infrared (NIR) imaging method was established to monitor $\mathrm{VHH}$ and $\mathrm{VHH}$ conjugated nanoparticle kinetics in mice using a hybrid approach: kinetics in blood were assessed by direct sampling, and kinetics in kidney, liver, and brain were assessed by serial in vivo NIR imaging. These studies were performed under "basal" circumstances in which the VHH constructs and VHH-conjugated nanoparticles do not substantially interact with targets nor cross the blood brain barrier. Using this approach, we constructed a fivecompartment PK model that fits the data well for single VHHs, engineered VHH trimers, and iron oxide nanoparticles conjugated to VHH trimers. The establishment of the feasibility of these methods lays a foundation for future PK studies of candidate brain MRI molecular contrast agents.
\end{abstract}

Keywords: VHH; nanoparticles; near-infrared imaging; biodistribution; pharmacokinetic modeling

\section{Introduction}

Neurological disorders affect millions of people worldwide, but at present our ability to assess these disorders objectively and quantitatively is limited [1]. Improvements in the assessment of neurological disorders would allow for disease progression monitoring and provide direct assessment of candidate therapeutics [2-5]. The long-term goal of this project is to develop MRI molecular contrast agents that will cross the blood brain barrier (BBB) and label relevant extracellular and intracellular biomarkers in the brain parenchyma. In the process of discovering and optimizing necessary components of these contrast agents, we have synthesized nanoparticles that consist of an iron oxide nanoparticle (IONP) core conjugated with Polyethylene glycol (PEG) plus single domain antibodies from camelids (VHH) for specific targeting.

IONPs have been widely used for medical applications including cancer diagnosis and treatment [6,7], treatment of iron deficiency anemia [6], enhanced blood pool and tumor MRI imaging [8,9], MRI molecular imaging [10-13], and magnetic resonance angiography (MRA) [14]. Sillerud et al. synthesized a novel MRI contrast agent by conjugating superparamagnetic oxide nanoparticles (SPIONs) with anti-amyloid-beta precursor protein 
(A $\beta P P)$ antibodies to specifically target amyloid-beta plaques [15]. Iron oxide nanoparticles have also been functionalized with single-chain antibodies ( $\mathrm{scFv}$ ) against activated platelets for $\mathrm{T}_{1}$ and $\mathrm{T}_{2}$-weighted MRI of thrombi [10]. IONPs are considered relatively safe and do not induce cytotoxicity below $100 \mu \mathrm{g} / \mathrm{mL}$ in vitro [16]. MRI Molecular contrast agents based on iron oxide nanoparticles have good biocompatibility, at least in part because human blood and tissues are naturally rich in iron $[17,18]$. The FDA has approved an IONP, Ferumoxytol, for treatment of iron-deficiency anemia in patients with chronic kidney disease [19]. Ferumoxytol is also used off-label as a contrast agent for MR angiography in patients with impaired renal function as well [20] and no major safety concerns have been reported. In a widely cited publication, Kim et al. [9] demonstrated that homogenous size iron oxide nanoparticle cores for MR imaging could be synthesized at large scales. Their extremely small $3 \mathrm{~nm}$ iron oxide nanoparticles (ESIONs) were shown to have a high $r_{1}$ relaxivity of $4.78 \mathrm{mM}^{-1} \mathrm{~s}^{-1}$ at $3 \mathrm{~T}$ and low $\mathrm{r}_{2} / \mathrm{r}_{1}$ ratio of 6.12 , which maximizes the T1 contrast effect. ESIONs were tested using in vivo MRI. After tail vein injection of ESION $(2.5 \mathrm{mg} \mathrm{Fe} / \mathrm{kg})$, blood vessels were brightened on the T1-weighted MR images, confirming that ESIONs can enhance T1 relaxation and be used as a T1 MRI contrast agent. The iron oxide core of this prototype nanoparticle contrast agent was coated with PEG [21]. PEG is a common coating material that is used to prevent nanoparticle fouling in blood by reducing protein binding and to prolong circulation times by reducing clearance by the reticuloendothelial system (RES) [22].

Camelids, which include llamas, alpacas, and camels, produce functional antibodies devoid of light chains called heavy chain-only antibodies (HCAbs) [23,24]. The heavy chain of this kind of antibody is folded into three domains: the N-terminal domain that is variable in sequence, followed by a hinge region and two constant domains. HCAbs recognize their cognate antigen by one single domain, the VHH. VHHs have a very small size compared to other antibodies or functional antibody fragments. The molecular weight of a VHH is approximately $15 \mathrm{kDa}$, which is around $1 / 10$ of a conventional IgG's molecular weight, and about $50 \%$ of that of a single chain variable fragment $(\mathrm{ScFv})[25,26]$. VHHs have been used for in vivo imaging and therapeutics [25,26]. For example, Li et al. labeled anti-A $\beta 42$ and anti-Tau VHHs with Alexa488 fluorescent dye and visualized extracellular $A \beta$ and intracellular neurofibrillary tangles using 2-photon-microscopy [27]. Vandesquille et al. conjugated a VHH (R3VQ)-targeting AB with gadolinium to allow MRI detection of $A \beta$ in post-mortem mouse brain [28]. Rincon et al. used VHHs to lower $A \beta$ levels with AAV-based delivery of anti-BACE1 VHH into the CNS of a cerebral amyloidosis mouse model [29]. VHHs against SARS-CoV-2, which could bind spike protein receptor binding domain, were recently developed as potential therapeutics for coronavirus outbreaks [30-33]. A humanized divalent VHH targeting von Willebrand factor (Caplacizumab) was recently approved by the FDA for treatment of acquired thrombotic thrombocytopenic purpura [34,35]. Importantly, VHHs show low immunogenicity risk profile before humanization [36]. For human therapeutic purposes, VHHs have been humanized to further lower the risk of immunogenicity [37]. For example, the safety of Caplacizumab has generally been good [38].

Pharmacokinetics (PK) is the study of drug absorption, distribution, metabolism, and excretion [39]. Pharmacokinetic and biodistribution characteristics are important parameters to consider when designing and testing novel nanoparticles to achieve an appropriate level of nanoparticles in the target tissue site. Nanoparticles with either extremely short or extremely long circulation time are generally considered non-optimal; nanoparticles with extremely short circulation time may not have enough time to penetrate target tissue sites, while nanoparticles with extremely long circulation time could cause off-target tissue toxicity and reduce signal-to-noise ratio due to background signal [40-43]. Thus, it is helpful to measure PK characteristics at an early phase in the project development so that this information can be used to optimize nanoparticle design.

Multiple approaches have been used to acquire PK and biodistribution data from in vivo experiments. Plasma and tissue sampling followed by inductively coupled plasma 
mass spectrometry (ICP-MS) are often used for in vivo distribution and PK studies. In prominent examples of this approach, Lankveld et al. assessed silver nanoparticles using ICP-MS to determine the silver content in organs for their tissue distribution study [44]. Xue et al. also used ICP-MS to study the tissue distribution of iron oxide nanoparticles in mice [45]. This approach, however, is invasive and requires sacrificing animals at multiple time points, which introduces inter-animal variations in data. Instead, various non-invasive imaging methods including PET, SPECT/CT, and MRI have been used to help trace distribution and clearance patterns [46-48]. While MRI may be an imaging modality of choice for diagnostic studies, it is expensive, requires lengthy anesthesia times for animals, and has relatively poor time resolution for use in PK studies. PET and SPECT are also relatively expensive imaging methods and raise radiation safety concerns. Near infrared (NIR) imaging has been proposed as an alternative method to study pharmacokinetics and tissue distribution to facilitate nanoparticle development [40]. Compared with the aforementioned methods, NIR is a less-expensive, faster, and safer method, which can be used to investigate nanoparticles' in vivo behavior in appropriate small animal models [40]. PK models use a system of mathematical equations to describe drug pharmacokinetics. In this study, the PK model was used to describe the distribution and excretion of VHHs and nanoparticles in mice. We used a common type of PK modeling called compartment modeling, which is based on the simplifying assumption that each 'compartment' (e.g., kidney, liver) is homogenous. Compartment models have been widely used for oncology, disease diagnosis, and imaging studies $[49,50]$. This paper combined near infrared imaging and multi-compartment model to study the pharmacokinetics of VHHs and IONPs in vivo.

This study establishes a foundation to understand the PK of VHHs and IONPs. In this study, IONPs conjugated to VHHs and labeled with a NIR fluorescent dye were injected intravenously (IV) into mice. The PKs of VHHs alone and VHH-conjugated IONPs were monitored using a high resolution NIR scanner. Fluorescence signal change in mouse brain, kidney, and liver were imaged over a period of 2 days post injection to qualitatively and quantitatively understand the PK of our nanoparticles. A five-compartment PK model was constructed to describe the relationship between in vivo PK and hydrodynamic size following single bolus IV injection. It was found that increasing VHH and nanoparticle size results in a switch from kidney-dominant clearance to liver-dominant clearance, which is consistent with past findings. The use of mathematical PK models provides a quantitative method to study the relationship between PK parameters and nanoparticle/VHH sizes and can be used to explore the in vivo pharmacokinetics and distribution of other VHHs and nanoparticles for future studies. This PK model will be incorporated and modified for describing novel VHH-IONP in vivo PK characteristics during the ongoing development of future brain MRI molecular contrast agents.

\section{Results}

\subsection{VHH and VHH-Conjugated Nanoparticle Characterization}

VHH singlet and VHH triplet products had characteristics consistent with expectation. Twenty-two $1 \mathrm{~mL}$ elution fractions were collected from a Superdex 75 size exclusion chromatography column. Peak fractions of purified VHH singlet and VHH triplet were collected for FNIR conjugation. VHH singlet peaked at fraction 11 and VHH triplet peaked at fraction 9 (Figure S1a). Based on the protein size standards, VHH singlet and VHH triplet eluted from the columns as expected based on their calculated sizes of $12.7 \mathrm{kDa}$ and $36.1 \mathrm{kDa}$, respectively.

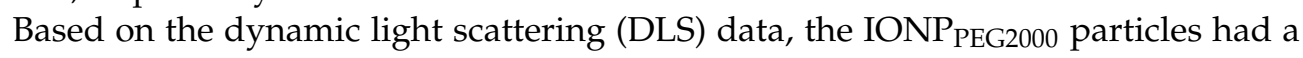
hydrodynamic radius of 6.4-6.7 $\mathrm{nm}$ before and 7.0-7.6 nm after conjugation with VHH triplet (Figure S1c). The 9th and 10th fractions from a Superose 6 Increase SEC column (optimized for larger particles) were used for IV injection and PK studies (Figure S1b). The

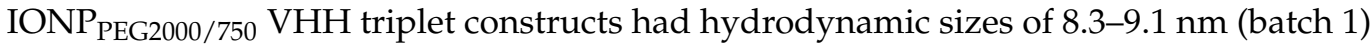
and 8.0-9.1 nm (batch 2) before, and 11.9-13.9 nm (batch 1) and 12.2-14.5 nm (batch 2) after 
conjugation with VHH triplet. The fifth, sixth, and seventh fractions from batch 1 and the sixth and seventh fractions from batch 2 from the Superose 6 Increase column were used for IV injection and PK studies (Figure S1b).

\subsection{In Vivo Pharmacokinetic Study Using NIR}

We optimized methods for NIR-based pharmacokinetic studies and then used these methods to acquire consistent in vivo pharmacokinetic data in mice. The NIR fluorescence images acquired using the Pearl system showed very low background fluorescence signal at $800 \mathrm{~nm}$, confirming that in the NIR, the intrinsic autofluorescence at this wavelength of light in the animals was negligible. Autofluorescence at $700 \mathrm{~nm}$ was higher, so we focused on $800 \mathrm{~nm}$ channel measurements for these experiments (Figure S2). It has been reported that the use of different NIR dyes can affect biodistribution of NIR-labeled VHHs [51] and monoclonal antibodies [52]. We tested IR-680RD dye (IRDye ${ }^{\circledR}$, Licor, Lincoln, NE, USA), IR-800CW dye (IRDye ${ }^{\circledR}$, Licor, Lincoln, NE, USA), and FNIR dye-conjugated nanoparticles and confirmed that the dyes can affect the apparent biodistribution (Figure S3). Mice had lower background autofluorescence at $800 \mathrm{~nm}$ channel than the $700 \mathrm{~nm}$ channel, so IR-800CW dye and FNIR dye were preferred over IR-680RD dye (Figure S3a). Comparing the IR-800CW dye and the FNIR dye, the signal quality and consistency was higher for the FNIR dye (Figure S3b,c). The stability of FNIR dye was tested by conjugating FNIR dye with VHH singlet. FNIR dye presented very good NIR signal stability (Figure S4a) and the VHH singlet-FNIR conjugate was stable in size over 14 days (Figure S4b).

NIR images of in vivo mice injected with four different FNIR dye conjugates (two VHHs and two IONPs) showed that the conjugates had different biodistributions in brain, kidney, and liver and were cleared from mice at different rates (Figure 1).
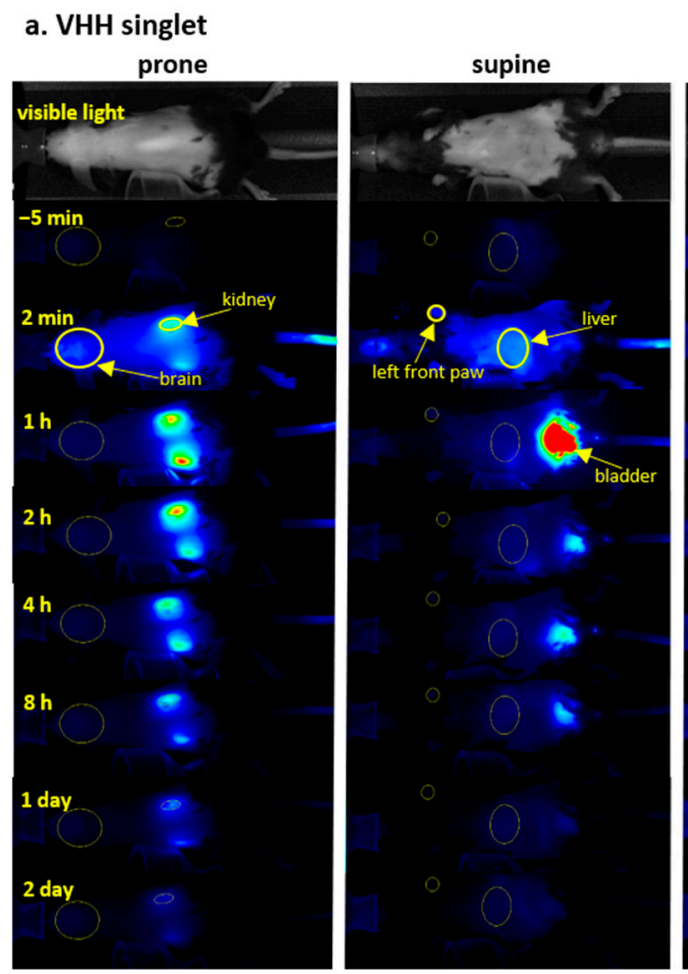

b. IONP ${ }_{\mathrm{PEG} 2000 / 750}$ VHH triplet

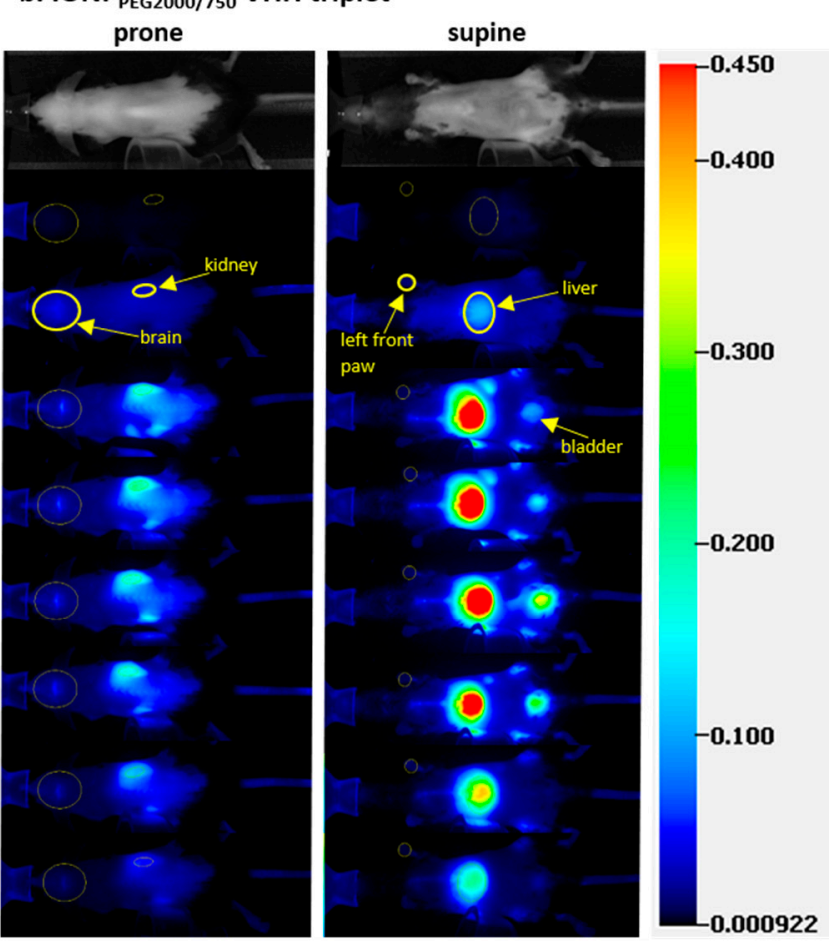

Figure 1. Representative in vivo serial fluorescence images and region of interest (ROI) analysis of singlet domain antibodies

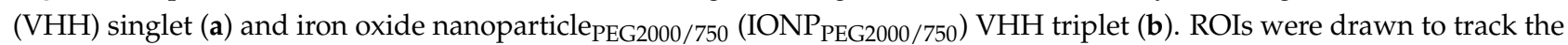
fluorescence signal change of major ROIs including kidney and brain (prone position), left front paw, and liver (supine image) over time. Scale bar represents near-infrared (NIR) image intensity measured by Pearl. (a) In vivo serial fluorescence prone and supine position images before and $2 \mathrm{~min}, 1 \mathrm{~h}, 2 \mathrm{~h}, 4 \mathrm{~h}, 8 \mathrm{~h}, 1 \mathrm{day}$, and 2 days after IV bolus injection of VHH singlet. (b) In vivo serial fluorescence prone and supine position images before and $2 \mathrm{~min}, 1 \mathrm{~h}, 2 \mathrm{~h}, 4 \mathrm{~h}, 8 \mathrm{~h}, 1 \mathrm{day}$, and 2 days after IV bolus injection of IONP $\mathrm{PEG}_{2000 / 750} \mathrm{VHH}$ triplet. 
Regions of interest (ROIs) of major organs including brain, kidney, and liver were drawn on the images acquired before, $2 \mathrm{~min}, 1 \mathrm{~h}, 2 \mathrm{~h}, 4 \mathrm{~h}, 8 \mathrm{~h}, 1$ day, and 2 days after IV injection at both prone and supine positions of mice (Figure 1a for VHH singlet, Figure $1 \mathrm{~b}$ for $\mathrm{IONP}_{\text {PEG2000/750 }} \mathrm{VHH}$ triplet). The reliability of ROI drawing method was calculated on five representative mice injected with $\mathrm{VHH}$ singlet (Figure S5). ROIs were drawn on the images two times on 2 different days. The Pearson correlation of the results from the two ROI drawings was very close to 1 , indicating almost perfect reliability of the ROI drawing method. The fluorescence intensities of each organ were measured for PK analysis. Kidney intensities were multiplied by two to represent both kidneys. To analyze the relative NIR signal changes across mice injected with different FNIR dye conjugates, which had different absolute NIR intensities, the main ROI fluorescence signals were normalized using left front paw signals at 2 min post injection as internal controls values. We found this approach to be more reliable than using intrinsic fluorescence of the injected material or local tail fluorescence values. For VHH singlet, the pharmacokinetic plots of kidney and liver showed that kidneys and liver had similar uptake, but kidneys had much slower fluorescence intensity decrease rate than liver, indicating that kidneys were the major organ for VHH singlet clearance (Figure 2a). For VHH triplet, the pharmacokinetic plots of kidney and liver showed that kidneys and liver had similar uptake and clearance rates, indicating that kidneys and liver both contribute to the clearance (Figure 2b). For IONP PEG2000 VHH triplet and IONP $_{\text {PEG2000/750 }} \mathrm{VHH}$ triplet, the pharmacokinetic plots of kidney and liver showed that liver had much larger uptake of nanoparticles than kidneys, indicating that liver was the main organ for the IONP-VHH conjugate clearance (Figure 2c,d). There were only modest differences in kinetics between the two different PEG coatings that were used to make the IONPs water soluble and serve as linkers for VHH conjugations. Particles coated with PEG2000 vs. particles coated with a 1:1 ratio of PEG2000 to PEG750 had similar kinetics with predominant liver uptake and biphasic clearance from the brain compartment.

The relationship between dose and kinetics was also explored using VHH triplet as an example (Figure 3). In this experiment, a higher dose $\mathrm{VHH}$ triplet at a concentration of $24.23 \mu \mathrm{M}$ was intravenously injected into six mice and NIR images were taken at the same time points as in other experiments. Lower dose $(4.75 \mu \mathrm{M})$ and higher dose $(24.23 \mu \mathrm{M}$, $\sim 5 \mathrm{x}$ lower dose) VHH triplet showed similar signal kinetics over all compartments. Higher dose and lower dose $\mathrm{VHH}$ triplet had very similar calculated kidney ratios and liver ratios, indicating dose-linearity of kinetics for VHH triplet.

All mice injected with $\mathrm{VHH}$ singlet, $\mathrm{VHH}$ triplet, IONPPEG2000 $\mathrm{VHH}$ triplet, and $\mathrm{IONP}_{\mathrm{PEG} 2000 / 750} \mathrm{VHH}$ triplet appeared healthy. No overt behavioral abnormalities were noted and veterinary intervention was not required.

\subsection{Blood Clearance Measured by NIR}

A limitation of the NIR fluorescence imaging approach was that we were unable to consistently assess the PK in blood. We initially tested the assumption that PK in peripheral tissues such as paw and tail would reflect PK in blood, but this turned out not to be correct; clearance from blood was substantially faster than peripheral tissues such as paw. Signal in ROIs containing heart and tongue muscle were too low to use for consistent model fitting $[47,48]$ (Figure 1). Therefore, we adopted a hybrid approach and measured PK in blood by direct sampling of blood from separate groups of mice sacrificed at multiple time points. Blood was sampled at $1 \mathrm{~min}, 5 \mathrm{~min}, 10 \mathrm{~min}, 15 \mathrm{~min}, 30 \mathrm{~min}$, and $1 \mathrm{~h}$ after IV injection and quantified using ROIs drawn on the NIR images of the ex vivo blood (Figure 4).

Then, the blood clearance curves were fitted using a single exponential equation (Figure 5). The NIR fluorescence images of ex vivo blood indicated fast blood clearance rate of VHHs and slower rate of VHH-IONP. Most of the materials were cleared out of the blood within the first $1 \mathrm{~h}$ post injection. The fitted half-lives were $7.09 \mathrm{~min}, 2.86 \mathrm{~min}$, and 1.94 min for IONP PEG2000 $\mathrm{VHH}$ triplet, VHH triplet, and VHH singlet respectively. 

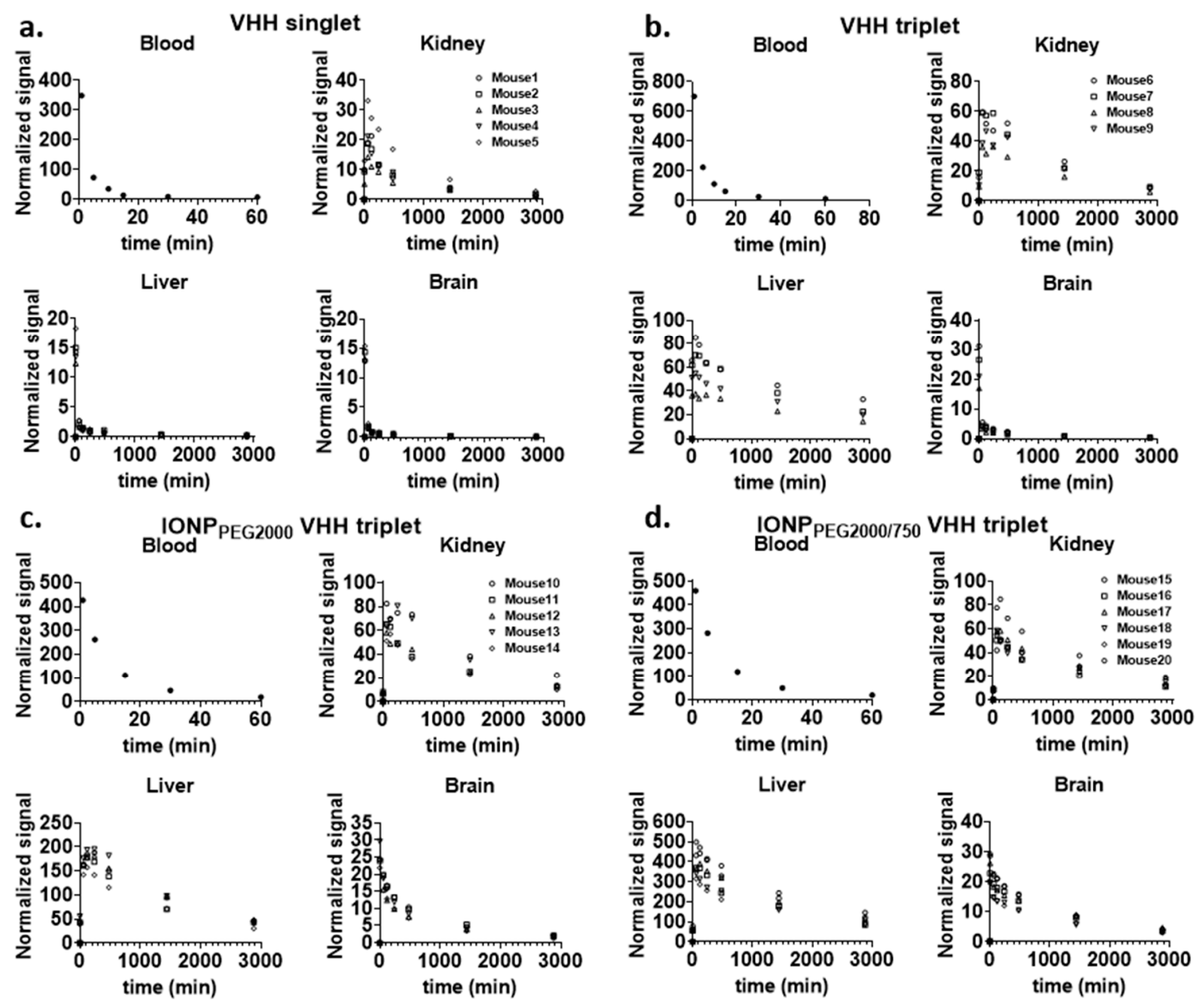

Figure 2. Major ROIs in vivo fluorescence signal changes over time. NIR signal change over time of major ROIs including blood, kidney, liver, and brain. (a) VHH singlet (five mice), (b) VHH triplet (four mice), (c) IONP PEG2000 VHH triplet

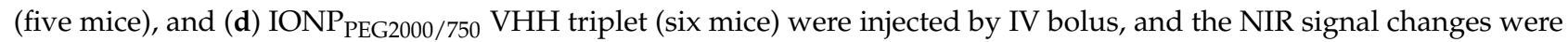
monitored in major ROIs.

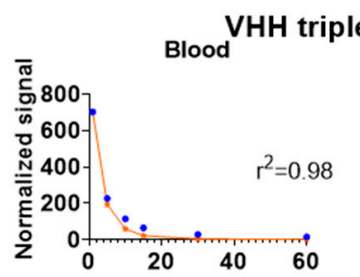

time (min)

- Measurement * Fitting

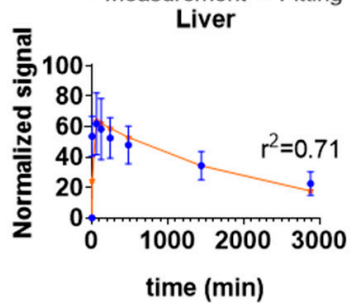

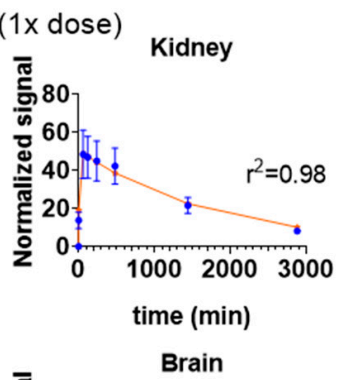

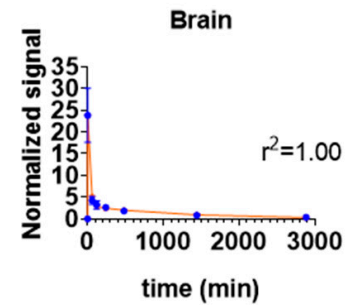

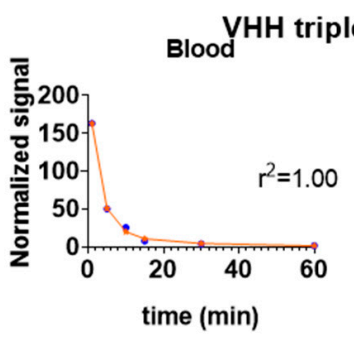

Liver

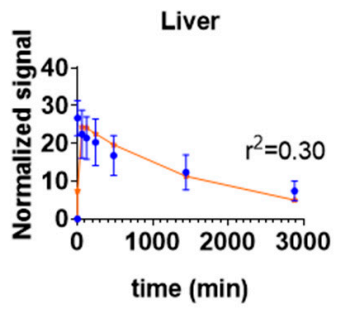

Kidney

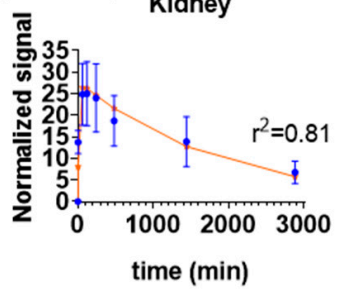

Brain

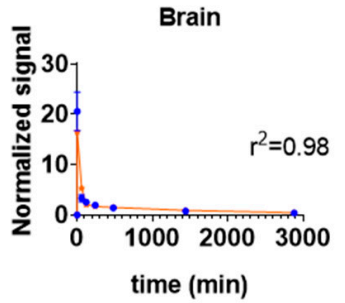

Figure 3. Dose-linearity testing: Fitting (red lines) of the five-compartment model solutions to the VHH triplet (1x dose) and VHH triplet (5x dose) measured data (blue symbols). The fitting-based kidney ratio and liver ratio are 37.18 and 33.11 for VHH triplet (5x dose) $(n=6)$, and 25.74 and 40.80 for VHH triplet (1x dose) $(n=4)$. Kidney ratio and liver ratio for VHH triplet ( $5 \mathrm{x}$ dose) and VHH triplet ( $1 \mathrm{x}$ dose) are of the same order and similar to each other. Error bars represent standard deviations. 


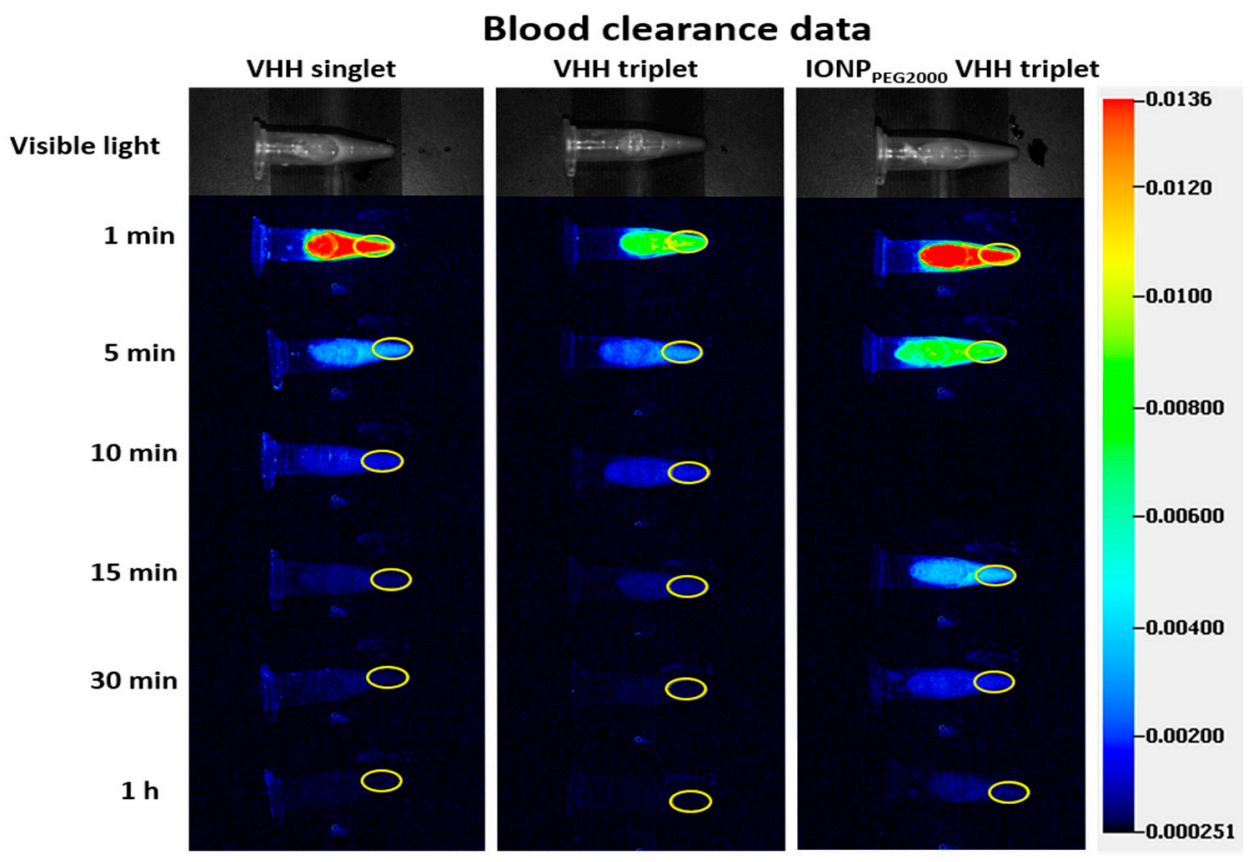

Figure 4. Ex vivo fluorescence images of blood. Scale bar represents NIR image intensity measured by Pearl. Mouse blood was collected at $1 \mathrm{~min}, 5 \mathrm{~min}, 10 \mathrm{~min}, 15 \mathrm{~min}, 30 \mathrm{~min}$, and $1 \mathrm{~h}$ after intravenous (IV) injection of VHH singlet and VHH triplet. Mouse blood was collected at $1 \mathrm{~min}, 5 \mathrm{~min}, 15 \mathrm{~min}, 30 \mathrm{~min}$, and $1 \mathrm{~h}$ after IV injection of IONP $\mathrm{PEG}_{2000} \mathrm{VHH}$ triplet. ROIs were drawn for NIR signal analysis.

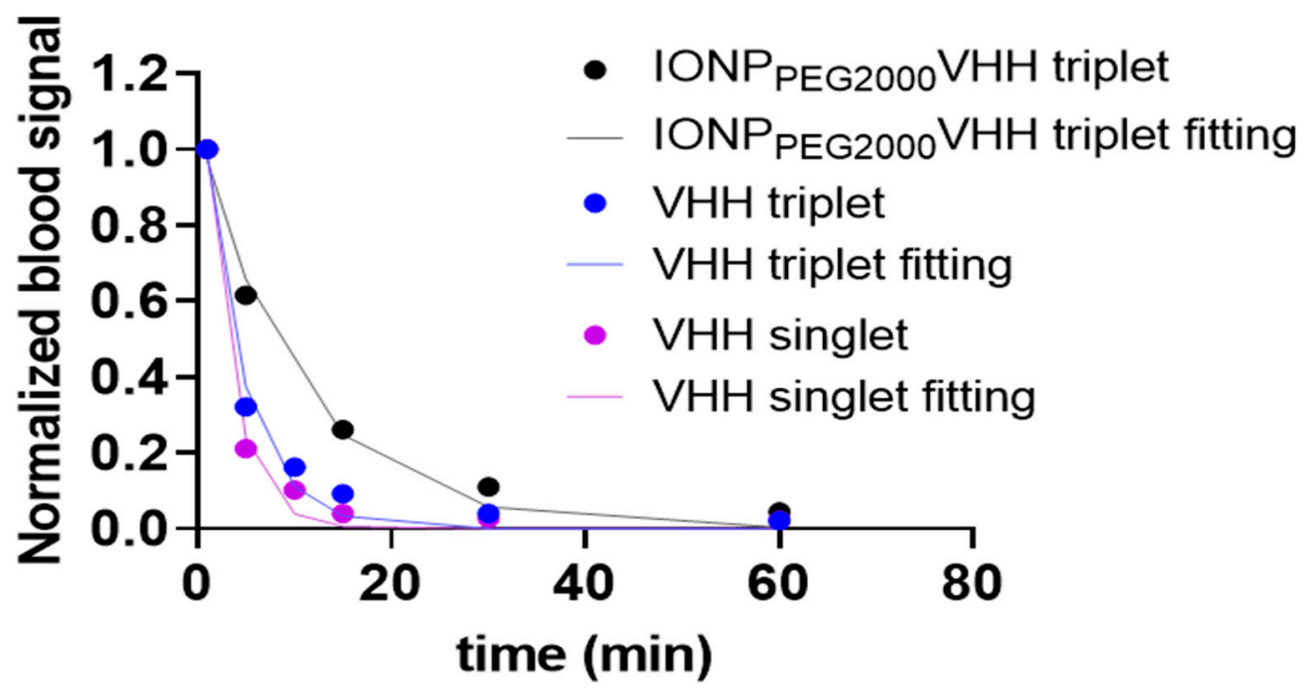

Figure 5. Blood clearance data and single exponential fitting. The NIR signals of VHH singlet, VHH triplet, and IONP $\mathrm{PEG}_{2000} \mathrm{VHH}$ triplet in mouse blood after IV bolus injection. The NIR signals were measured at $1 \mathrm{~min}, 5 \mathrm{~min}, 10 \mathrm{~min}, 15 \mathrm{~min}, 30 \mathrm{~min}$, and $1 \mathrm{~h}$ post injection for $\mathrm{VHH}$ singlet and $\mathrm{VHH}$ triplet. The NIR signals were measured at $1 \mathrm{~min}, 5 \mathrm{~min}, 15 \mathrm{~min}, 30 \mathrm{~min}$, and $1 \mathrm{~h}$ post injection

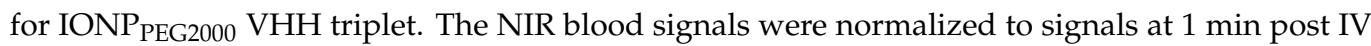
injection and fitted using the single exponential equation $y=a * e^{-\frac{x}{\tau}}$. The time constant $\tau$ best fit values were $2.80 \mathrm{~min}, 4.13 \mathrm{~min}$, and $10.24 \mathrm{~min}$ for $\mathrm{VHH}$ singlet, VHH triplet, and IONP PEG2000 $_{2}$ VHH triplet.

\subsection{Mathematical Modeling}

This mathematical PK model described the in vivo PK of FNIR-VHHs and FNIR-IONPVHHs by segmenting the body into five main compartments and the five compartments 
were related through mass transfer (Figure 6). X1, X2, X3, X4, and X5 were the amounts of conjugates in blood, kidney, liver, brain 1, and brain 2 compartments. k12, k21, k13, $\mathrm{k} 31, \mathrm{k} 14$, and $\mathrm{k} 41$ were the forward and reverse first-order transfer rate constants for the intercompartment change between blood compartment and kidney, liver, and brain compartments. $\mathrm{k} 45$ and $\mathrm{k} 54$ were the forward and reverse first-order transfer rate constants for intercompartment change between brain 1 and brain 2 compartments. K10 was the first-order rate constant for clearance. The initial condition of blood compartment was used to describe the bolus IV injection to the blood compartment and set to be the normalized conjugate fluorescence intensity (normalized by left front paw signal intensity). The initial conditions of kidney, liver, paw, and brain compartments were set to be 0 , based on the assumption that the nanoparticles/VHHs enter these organs only through the blood. The five ordinary differential equations (ODEs) were established to describe the mass transfer of VHHs/IONPs between the five compartments and their clearance.

$$
\begin{gathered}
\frac{d X 1}{d t}=-\left(k_{12}+k_{13}+k_{14}+k_{10}\right) X_{1}+k_{21} X_{2}+k_{31} X_{3}+k_{41} X_{4} \\
\frac{d X 2}{d t}=-k_{21} X_{2}+k_{12} X_{1} \\
\frac{d X 3}{d t}=-k_{31} X_{3}+k_{13} X_{1} \\
\frac{d X 4}{d t}=-\left(k_{41}+k_{45}\right) X_{4}+k_{14} X_{1}+k_{54} X_{5} \\
\frac{d X 5}{d t}=-k_{54} X_{5}+k_{45} X_{4}
\end{gathered}
$$

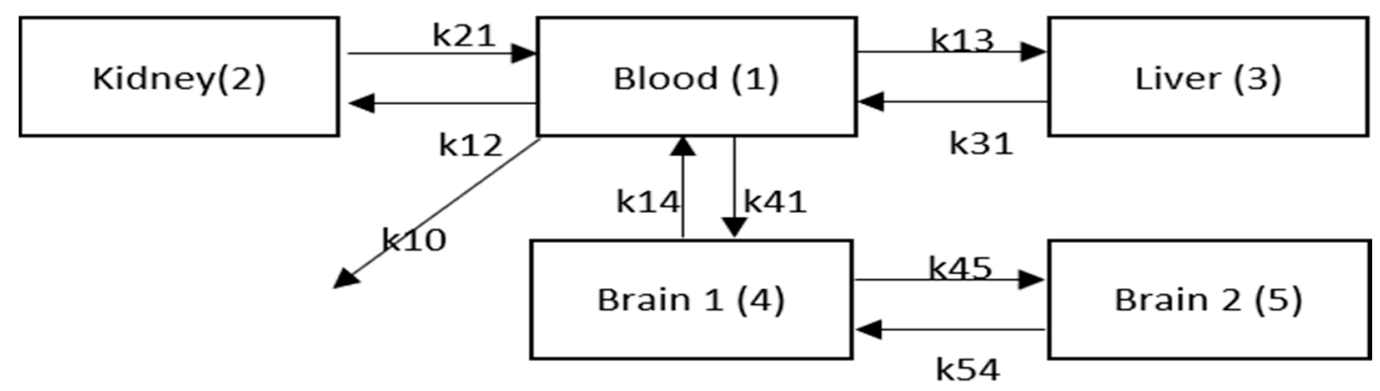

Figure 6. Schematic graph for the five-compartment mathematical model. This schematic graph describes the in vivo kinetics of VHHs/IONPs, including uptake, clearance and intercompartment exchanges. This model is characterized by a system of five ordinary differential equations (ODEs). k12, k21, k13, k31, k14, and k41 are the forward and reverse first-order transfer rate constants for the intercompartment change between blood compartment and kidney, liver, and brain compartments. k45 and k54 are the forward and reverse first-order transfer rate constants for intercompartment change between brain 1 and brain 2 compartments. $\mathrm{k} 10$ is the first-order rate constant for clearance from blood.

The normalized averaged PK data were fitted using the five-compartment model. Figure 7 and Table 1 show the optimal model fitting for the two VHH constructs and the two VHH conjugated IONPs. The fitting corresponded well with the normalized data. A four-compartment model with only one brain compartment was tested first (Figure S6). However, with only one brain compartment, the fitting did not match the trend of brain signal change as well (Figures S7, and S8). A second brain compartment was added to better fit the brain signal change (Figures 6 and 7). Small sample-corrected Akaike Information criteria (AICc) values were $-35.90,-16.85,-20.47$, and -41.29 for four compartment fitting and $-41.59,-22.62,-27.48,-39.09$ for five-compartment model fitting of VHH singlet, VHH triplet, IONP PEG2000 $_{2 H H}$ triplet, and IONP PEG2000/750 $_{2 H H}$ triplet respectively. Because models with lower AIC values are preferred, the five-compartment model was selected. No additional kidney or liver compartments were added because the benefit in 
terms of fitting was limited, and not justified based on the increased complexity of the model. Similarly, there was no additional benefits of adding kinetic parameters representing direct clearance from kidney $(\mathrm{k} 20)$ or liver $(\mathrm{k} 30)$ in terms of model fitting, and these rate constants could not be independently constrained by the acquired data. Therefore, these kinetic parameters were not included in the final models. For VHHs/nanoparticles that do not appreciably cross the BBB, PK of paw and brain compartments were similar (Figure S9), so the paw compartment was not included in the model separately. Table 1 shows the optimal sets of fitting parameters for the two VHHs and the two IONPs. Table 2 shows the $\mathrm{r}^{2}$ values and calculated kidney and liver uptake/clearance ratios, which were calculated by Equations (6) and (7).

$$
\begin{gathered}
\text { Kidney ratio }=\frac{k_{12}}{k_{21}} \\
\text { Liver ratio }=\frac{k_{13}}{k_{31}}
\end{gathered}
$$
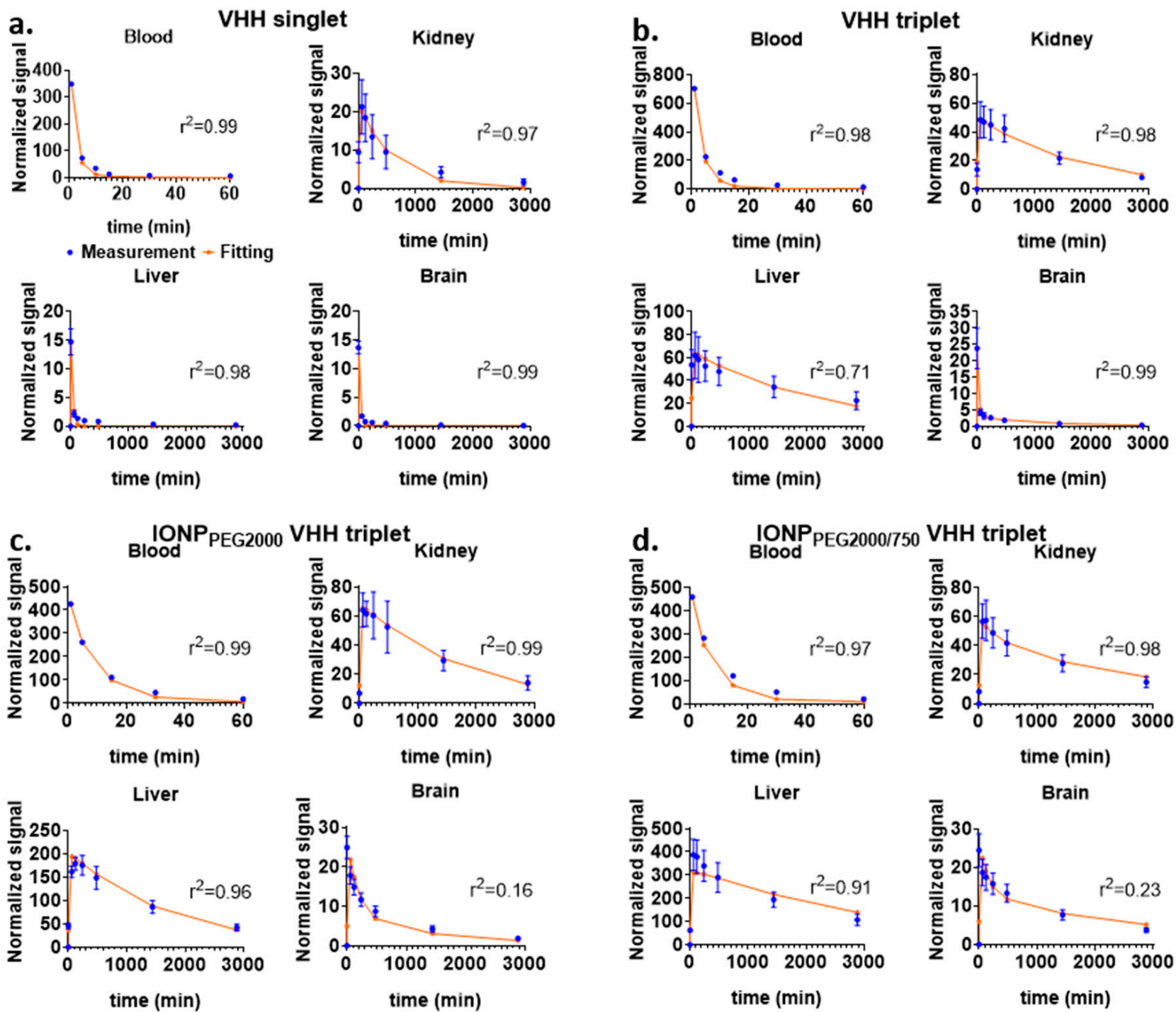

Figure 7. Fitting of the five-compartment model solutions to the experimentally measured fluorescence data. Fitting of the model simulated solutions (red line) and the measured normalized NIR signals (blue dot) of major organs after IV

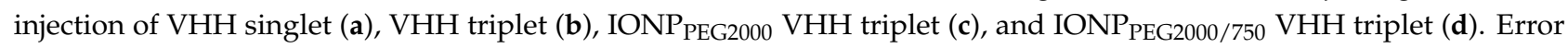
bars represent standard deviations. 
Table 1. Five-compartment model-fitted parameters for VHH singlet, VHH triplet, IONP $\mathrm{PEG}_{2000}$

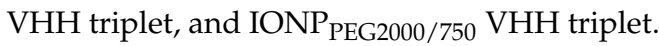

\begin{tabular}{cccccccccc}
\hline & $\mathbf{k 1 2}$ & $\mathbf{k 2 1}$ & $\mathbf{k 1 3}$ & $\mathbf{k 3 1}$ & $\mathbf{k 1 4}$ & $\mathbf{k 4 1}$ & $\mathbf{k 4 5}$ & $\mathbf{k 5 4}$ & $\mathbf{k 1 0}$ \\
\hline VHH singlet & 0.02060 & 0.0018 & 0.0317 & 0.0502 & 0.0302 & 0.0847 & 0.3678 & 0.9212 & 0.3000 \\
VHH triplet & 0.0173 & 0.0007 & 0.0225 & 0.0006 & 0.0232 & 0.0625 & 0.0027 & 0.0010 & 0.2000 \\
IONP PEG2000 & 0.0156 & 0.0019 & 0.0466 & 0.0019 & 0.0063 & 0.0058 & $7.51 \mathrm{E}-05$ & 0.9870 & 0.0300 \\
$\begin{array}{c}\text { VHH triplet } \\
\text { IONP PEG2000/750 } \\
\text { VHH triplet }\end{array}$ & 0.0155 & 0.0032 & 0.0836 & 0.0024 & 0.0072 & 0.0063 & 0.0011 & 0.0050 & 0.0150 \\
\hline
\end{tabular}

Comparing the values of kidney ratio and liver ratio, the kidney intake/clearance ratio was much larger than liver ratio for $\mathrm{VHH}$ singlet, the kidney and liver ratios were similar for $\mathrm{VHH}$ triplet, and the liver ratio was much larger than kidney ratio for both VHH-conjugated nanoparticles (Table 2). As expected, as the size increased from VHH singlet to IONP $\mathrm{PEG}_{2000 / 750} \mathrm{VHH}$ triplet, the fitted liver ratio increased compared with the kidney ratio, replacing the kidney ratio's dominant position. This is consistent with previous findings that when molecular size is below the renal filtration, molecules are mostly filtered out of the body through the kidneys. As molecular size increases and passes the renal filtration cutoff, liver plays a more substantial role in clearance.

Table 2. Five-compartment model fitting $\mathrm{r}^{2}$ values of blood, kidney, liver, and brain ROIs. Kidney and liver uptake/clearance ratios are also calculated for each molecule.

\begin{tabular}{lcccccc}
\hline & $\mathbf{r}^{2}$ Blood & $\mathbf{r}^{2}$ Kidney & $\mathbf{r}^{2}$ Liver & $\mathbf{r}^{2}$ Brain & Kidney Ratio & Liver Ratio \\
\hline VHH singlet & 0.9888 & 0.9718 & 0.9802 & 0.9942 & 11.2928 & 0.6317 \\
VHH triplet & 0.9803 & 0.9829 & 0.7086 & 0.9975 & 25.7424 & 40.8006 \\
IONP PEG2000 & 0.9949 & 0.9918 & 0.9592 & 0.1556 & 8.38232 & 24.1638 \\
$\begin{array}{l}\text { VHH triplet } \\
\text { IONP PEG2000/750 }\end{array}$ & 0.9749 & 0.9831 & 0.9150 & 0.2268 & 4.8673 & 35.4626 \\
VHH triplet & & & & & \\
\hline
\end{tabular}

\subsection{Multidose Experiment and Model Fitting}

As a test of the accuracy of the model, we used single dose-based kinetic parameters to predict the kinetics after multiple doses. An experiment with both single-dose and multidose IV injection was performed using VHH triplet. Single dose PK measurements were performed by intravenously injecting $0.1 \mathrm{~mL} \mathrm{VHH}$ triplet into three mice and an additional group of five mice received three doses of the same $0.1 \mathrm{~mL} \mathrm{VHH}$ triplet with time intervals of $5 \mathrm{~min}$ between doses. The normalized averaged single dose mice data was fitted using the five-compartment model. The five-compartment model fitted the single dose data well, with $\mathrm{r}^{2}$ values of $0.9947,0.9747,0.5998$, and 0.9995 for blood, kidney, liver, and brain compartment, respectively. Then the predicted multidose kinetics were calculated based on the model with no additional free parameters through superposition. Finally, the single dose model-based predicted multidose kinetics were compared with the measured multidose kinetics (Figure 8a). The model-based predicted multidose kinetics closely followed the trend of the experimentally measured multidose kinetics (Figure $8 \mathbf{b}$ ). Thus, the multidose data was moderately well fit by the model based on PK parameters derived from the single dose data, with $\mathrm{r}^{2}$ values of $0.5529,0.4701$, and 0.1855 for the kidney, liver, and brain compartments. 
a. Single dose measurement and fitting

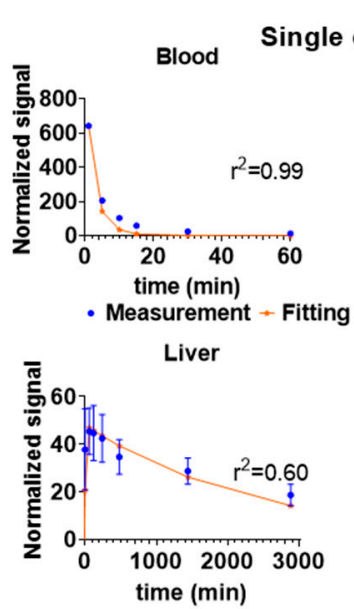

b. Model calculated vs measured multidose PK $(5 \mathrm{~min}$ interval 3 doses)

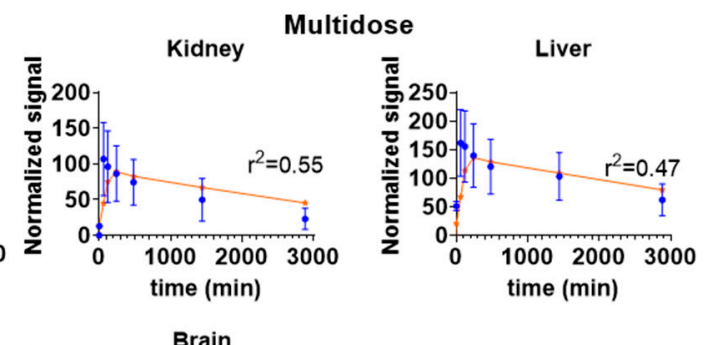

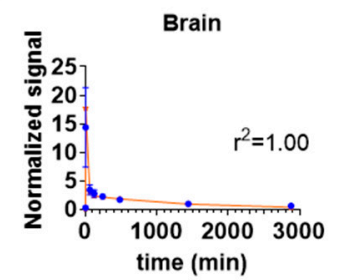
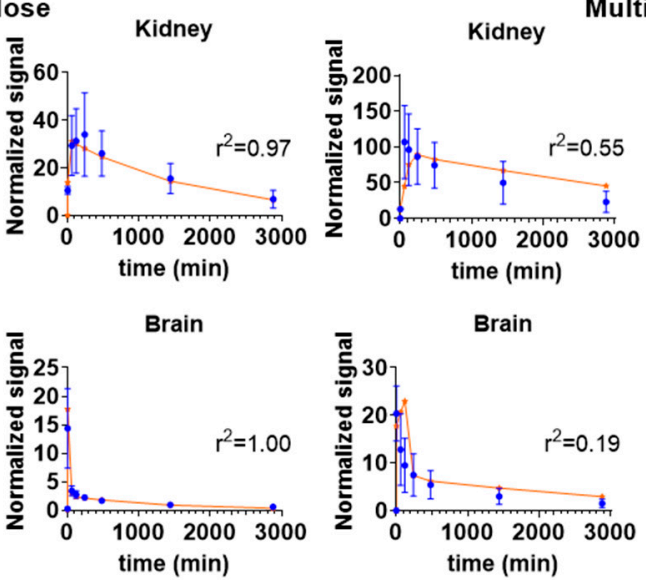

Figure 8. Prediction of multidose regimen using five-compartment model fitted using parameters from single-dose experiment. (a) NIR signal change over time after single IV bolus injection ( $n=3$ mice, blue dot) and the fitting solution (red line) calculated based on the five-compartment model. (b) Experimentally measured fluorescence signal ( $n=5$ mice, blue dot) and prediction of multidose signal (red line) based on the five-compartment model single dose fit with no free parameters. Three bolus IV injections with time intervals of $5 \mathrm{~min}$ between doses was performed for the multidose experiment. Error bars represent standard deviations.

\section{Discussion}

In summary, we found that the kinetics of VHHs and VHH-conjugated iron oxide nanoparticles were clearly related to their size. The smallest sized VHH singlets were cleared mostly by the kidneys. As the size increased, the liver became progressively more dominant in the uptake and clearance of VHHs/nanoparticles. These findings are consistent with the hypothesis that the NIR imaging for PK study can provide information about relative nanoparticle/VHH concentration changes in mouse tissues and are in line with previous knowledge about renal filtration. It is known that the threshold of glomerular filtration for macromolecules and nanoparticles is between 5 and $8 \mathrm{~nm}$ with progressively decreasing filtration as molecular size increases [53-55]. The PK model constructed in this study had five compartments: blood, kidney, liver, brain, and brain extracellular. For model fitting, blood compartment kinetic data were needed. However, NIR signal from the blood compartment could not be directly measured using the Pearl system in vivo. Ex vivo experiments were therefore performed to understand the blood NIR signal change after IV injection of VHHs and to help with the model fitting. Thus, this approach should be considered a hybrid, with direct sampling of blood, and serial NIR imaging-based sampling of other compartments.

This study found that the relative value of uptake/clearance of liver and kidney ratios based on the fitted PK parameters can be used as reference to understand the relationship between $\mathrm{VHH} /$ nanoparticle sizes and in vivo behavior. Because we are most interested in nanoparticle/VHH's kinetics in the brain for future nanoparticle/VHH brain targeting experiments, a second brain compartment was added to the model. This model describes the nanoparticle/VHH kinetics in the brain more accurately than a model with a single brain compartment. We demonstrated the robustness of the fitted PK model by testing linearity (Figure 3) and multidose conditions (Figure 8).

The VHHs and nanoparticles characterized in this study are prototypes for the design of the final contrast agents. Because we have not yet achieved BBB crossing, the binding of the VHHs and nanoparticles to their targets in the brain is not described in this paper. Instead, to facilitate development of the final contrast agents with optimal delivery capacity and biosafety, this study focused on understanding the relationship between in vivo pharmacokinetic (PK) characteristics and size of these prototype VHHs and nanoparticles. 
It was found that in the NIR range of around $650 \mathrm{~nm}$ to $900 \mathrm{~nm}$ wavelength, biological tissues have the lowest absorption coefficient and minimum tissue autofluorescence [56,57]. Fluorescence dyes with excitation/emission wavelength in the near-infrared range have deeper penetration depth than visible light and provide higher signal to background ratio with decreased background noise and modest autofluorescence [58-60]. The advantage of our study is that it uses NIR to capture images from individual mice post IV injection over time. The time-series images collected from individual mice reduce variations between mice and improve data consistency. Also, the number of mice used was greatly reduced compared with the conventional methods for PK data collection (e.g., ICP-MS measurement of iron content). For a conventional ICP-MS-based PK study, multiple animals need to be sacrificed to collect data at each time point $[44,45]$. In our NIR imaging-based PK experiment, 20 mice were used to collect the main data: five mice for each of four $\mathrm{VHH}$ or VHH-nanoparticle constructs. To get the same amount of data, a conventional PK study would have required 140 mice (five mice $\times$ four constructs $\times$ seven time points) in total. NIR imaging also has the advantages of fast imaging speed, low cost, and modest regulatory oversight requirements compared to other imaging methods used for PK studies such as PET, SPECT, and MRI. A limitation of NIR imaging approaches in the past has been the quality of dyes available. Compared with commercially available dye IR- $800 \mathrm{CW}$, the FNIR we used has advantages including reduced aggregation and dramatically increased NIR emission brightness [61]. FNIR dyes have been used to label monoclonal antibodies to visualize the biodistribution and clearance following IV injection in mice [52].

Modeling pharmacokinetics with mathematical models helps with decision making in nanoparticle development. Pharmacokinetic modeling has been widely used to guide drug and nanoparticle development [62,63]. Compartment models are designed to simplify the complex processes related to drug distribution and elimination in the body [64]. In compartment models, drug tissue concentration is assumed to be uniform within a given hypothetical compartment. Tissues with similar PK characteristics are lumped into one hypothetical compartment. Compartment models have been used to understand drugs and nanoparticles in vivo PK [65-67]. Gadkar, K., et al. constructed a two-compartment model to guide antibody selection for $\mathrm{A} \beta$ reduction [62]. Uno, Y., et al. constructed a three-compartment model to estimate the interstitial concentration of talaporfin sodium [66]. Sim, H., et al. established a two-compartment model to study the relationship between tumor growth and drug uptake kinetics [68]. In this study, we established a multi-compartment model based on NIR images, which describes the PK of VHHs and nanoparticles in blood as well as other tissue compartments. This multi-compartment model will be used to guide future nanoparticle development and the compartments can be adjusted based on the study focus.

One limitation of this study is that the signal from NIR images does not reflect the absolute concentrations in the compartments of interest. The presence of skin and soft tissues reduces image quality by optical attenuation and scattering [59,60]. We propose that fluorescence signals provide information about the relative concentration kinetics in major ROIs, rather than exact concentration values. In addition, NIR methods are less amenable to assessing smaller compartments such as spleen or bone marrow. Clearly, NIR approaches are best suited for relatively short-term studies in small animals such as mice with little intrinsic skin pigmentation; in larger animals there is too much attenuation between the tissues of interest and the detectors. Longer term PK studies would be difficult because of the challenges of maintaining hair removal for more than a few days without compromising health.

Another substantial limitation is that we only characterized PK in relation to construct size. There are many other properties of IONPs including hydrophobicity, surface charge, and coating or conformation of nanoparticles/VHHs that could affect their PK and biodistribution $[6,8,22,45]$. We found minimal differences between IONPs coated with PEG2000 vs. a 1:1 ratio of PEG2000 to PEG750. Thus, there does not seem to be a major effect of the length of PEG coating in this case. Furthermore, the nanoparticles tested in this study 
are not our final product, and the binding properties of next generation nanoparticles will certainly influence the in vivo PK and will require modification of the model.

We acknowledge that we have not performed blood measurements for both IONPVHH constructs; we collected blood data for the IONP PEG2000 $_{2 H H}$ triplet but not the $\mathrm{IONP}_{\mathrm{PEG} 2000 / 750} \mathrm{VHH}$ triplet. Based on the findings that organ PK was essentially the same for these two IONP-VHH constructs, we used the blood data from IONPPEG2000 VHH triplet to constrain PK models for both constructs. This relies on the assumption that the blood clearance of the two IONPs were similar. Both models fit well, so this assumption seems reasonable.

There were several additional limitations. The precise stoichiometric relationships of iron oxide: PEG: VHH conjugates were not determined. We plan to use thermogravimetric analysis (TGA) to assess the nanoparticle stoichiometry in the future [69]. Also, opsonization/fouling of the nanoparticles in blood was not assessed in this study [70,71]. Our preliminary data (unpublished) indicate that similar PEG-coated IONPs remain stable in size over $24 \mathrm{~h}$ at $37^{\circ} \mathrm{C}$ in human plasma, suggesting minimal fouling. Furthermore, we did not collect urine or feces, thus excretion was not directly measured. Finally, we did not systematically assess toxicity. Toxicity of IONPs is concentration and exposure time-dependent [72,73]. In general, iron oxide nanoparticles are considered very safe, but potential risks of iron can be related to oxidative stress and potential risks of foreign proteins can include immune responses $[17,74]$. Cationic iron can increase the production of reactive oxygen species (ROS), which may react and damage cell membrane and DNA. The cytotoxicity of our IONPs will be explicitly assessed in the future. We have not performed multidose experiments with long enough intervals between doses to assess for potential immune-related toxicity of the llama VHH proteins.

For future experiments, we will study the PK and distribution of the nanoparticles with adjusted components including VHHs targeting specific brain proteins and BBB components. PK and clearance of updated nanoparticle designs will be measured using the NIR imaging method and will be fitted using the PK compartment model developed in this paper. More complex, possibly nonlinear, models including information about binding kinetics and binding capacities will also be developed. Such experiments will incorporate genetically manipulated mice expressing human brain proteins and BBB components. Thus, for experiments involving complex genetically manipulated animals, methods that reduce the number of mice needed are especially relevant. Differences between genetically manipulated mice and appropriately matched controls will help reveal whether there are differences in in vivo kinetics and clearance, indicating target engagement of nanoparticles with biomarkers in brain. The mathematical PK models will be used to design experiments involving injecting the optimized nanoparticles into mice and imaging the signal change in brain using MRI at time points after injection selected based on the PK modeling. Similarly, the radiological-pathological correlations between in vivo imaging findings and ex vivo histology results will be studied at time points selected based on the model results.

\section{Materials and Methods}

\subsection{Synthesis of $\mathrm{VHHs}$}

For this study, we synthesized VHH monomers of a nanobody called NB3 that did not bind any targets in wild-type mice using methods similar to those described in Esparza. et al. [30]. In addition, we produced a single polypeptide VHH heterotrimer that consisted of NB3, a (GGGS) 3 linker; NB3, a (GGGS) 3 linker; and another nanobody called $\mathrm{H} 1$ synthesized by Esparza et al. that also does not bind any targets in wild-type mice. The sequence and characteristics of these VHH constructs will be reported separately. These constructs were termed "VHH singlet" and "VHH triplet." Phagemid pHEN2 with VHH triplet or VHH singlet were transferred into the BL21(DE3)-competent E. coli cells (C2527I, New England BioLabs, Ipswich, MA, USA) (Figure S10). The competent cells were grown in terrific broth medium at $37^{\circ} \mathrm{C}$. Isopropyl $\beta$-d-1-thiogalactopyranoside (IPTG) at a final $1 \mathrm{mM}$ concentration was added to induce VHH expression when the 
$\mathrm{OD}_{600}$ reached 0.6. Following overnight expression, cells were pelleted by centrifugation and VHHs were extracted through periplasm extraction [30,75]. The 6x histidine-tagged VHHs were purified by Fast Protein Liquid Chromatography (FPLC) using a HisTrap ${ }^{\mathrm{TM}}$ FF Ni-NTA column (Cytiva, Marlborough, MA, USA). To further purify VHHs, they were size fractionated using a Superdex ${ }^{\mathrm{TM}} 75$ 10/300 GL column (Cytiva, Marlborough, MA, USA) with Phosphate Buffered Saline (PBS), pH 7.4, at a flow rate of $1 \mathrm{~mL} / \mathrm{min}$.

\subsection{Conjugation of FNIR Dye to VHH Constructs}

The NIR dye FNIR-Tag-NHS was provided by the Schnermann group [61]. Lysine groups on VHHs were labeled with FNIR dye through standard NHS conjugation. For conjugation of FNIR dye to VHH, a 1:1.5 molar ratio of VHH and FNIR dye were incubated together at room temperature for $2 \mathrm{~h}$. Following conjugation, the VHH-dye conjugate was purified from unincorporated label using a $5 \mathrm{~mL}$ HiTrap ${ }^{\circledR}$ desalting column (Cytiva, Marlborough, MA, USA) with PBS. Total protein concentration was measured using the Epoch microplate spectrophotometer (BioTek, Winooski, VT, USA) by measuring absorption at wavelength $280 \mathrm{~nm}$ and corrected using the theoretical extinction coefficient.

\subsection{Production of IONPs, Ligand Exchange, and Conjugation of VHH Constructs}

IONPs were generated by the thermal decomposition and ligand-exchanged methods described by Kim, et al. [9] (Supplementary methods). Two different approaches to ligand exchange were used, involving (1) PEG-Azide-2k, MW 2000 Da (Nanosoft Polymers, Winston-Salem, NC, USA) and (2) a 1:1 ratio of PEG-Azide-2k and PEG methyl ether, MW 750 Da (Sigma Aldrich, St. Louis, MO, USA). We developed two types of NPs. The

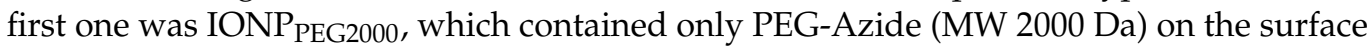
while the second type IONP PEG2000/750 comprised of both PEG-Azide (MW $2000 \mathrm{Da}$ ) and methoxy-PEG-ether (MW $750 \mathrm{Da}$ ). Solid state IONP $\mathrm{PEG}_{2000}$ and IONP $\mathrm{PEG}_{2000 / 750}$ were dissolved in $0.9 \%$ saline $+0.05 \%$ tween 80 solution and sonicated for $15 \mathrm{~min}$ followed by filtration through a $0.22 \mu \mathrm{m}$ syringe filter. Then, a Superose ${ }^{\mathrm{TM}} 6$ Increase 10/300 column (Cytiva, Marlborough, MA, USA) was used for size exclusion chromatography (SEC). Fractions corresponding to the eluted peak were collected. Hydrodynamic size of IONP was measured using the Dynapro ${ }^{\circledR}$ Nanostar ${ }^{\circledR}$ cuvette-based DLS instrument (Santa Barbara, CA, USA). FNIR dye and Dibenzocyclooctyne-amine (DBCO) were conjugated to VHH triplets at 1:1.5 molar ratio through standard NHS conjugation as described in Section 4.2. Peak fractions of IONPs were concentrated and conjugated with FNIR dye and DBCO-labelled VHH triplets via copper-free click chemistry for $24 \mathrm{~h}$ at room temperature [76,77].

The click chemistry allowed the reaction of DBCO-conjugated VHH triplets to the azide groups at the terminus of the PEG2000, yielding covalent attachment of VHH tripletDBCO to PEG-Azide-2k ligand-coated IONPs (Figure S11d). After $24 \mathrm{~h}$ incubation, the click-reaction was resolved through a Superose 6 Increase column with $0.9 \%$ saline $+0.05 \%$ tween 80 solution for size exclusion separation of unreacted constituents. Fractions at the peak of size exclusion were collected and their size was measured using DLS. The peak fractions corresponding to VHH-conjugated IONP were used for in vivo pharmacokinetic studies (Figure S1).

\subsection{Animals}

All animal experiments were conducted under protocols approved by the National Institute of Neurological Disorders and Stroke (NINDS)/National Institute on Deafness and Other Communication Disorders (NIDCD) Animal Care and Use Committee in the National Institutes of Health (NIH) Clinical Center. C57BL/6J female mice were purchased from Jackson labs at 6-12-weeks of age and used at 7-12 weeks of age. Twenty mice were randomized into four groups with four to six mice in each group. Anesthetized mice were injected via tail vein with VHH singlet (five mice), VHH triplet (four mice), $\mathrm{IONP}_{\text {PEG2000 }} \mathrm{VHH}$ triplet (five mice), or IONP $\mathrm{PEG}_{2000 / 750} \mathrm{VHH}$ triplet (six mice) for PK studies. Experiments were performed at the same time each day. The dark color fur coat of 
the strain of mouse used impedes the penetration of NIR light; therefore, the fur overlaying the regions of interest was removed by applying a topical depilatory cream above the brain, on the ventral and dorsal torso and tail of the mice 1 day prior to IV injection. Delayed skin hyperpigmentation was observed starting 4 days after hair removal.

\subsection{Injection of Nanoparticles}

Mice were anesthetized with $60 \%$ oxygen $/ 40 \%$ medical air gas mixture containing $5 \%$ isoflurane in an induction box. After a stable anesthesia plane was established, mice were maintained at $1.5-2 \%$ isoflurane level. Artificial tears ointment was applied to prevent eye injury due to drying. Mice were placed on an electrical heating pad to maintain body temperature. Nanoparticle conjugates (in $0.9 \%$ saline $+0.05 \%$ tween 80 solution) and VHHs (in PBS) with different sizes (12 $\mu \mathrm{M}$ VHH singlet, $4.75 \mu \mathrm{M}$ VHH triplet, IONP PEG2000 $\mathrm{VHH}$ triplet, IONP $\mathrm{PEG}_{\mathrm{PE00} / 750} \mathrm{VHH}$ triplet) were injected intravenously through single bolus injection at $0.1 \mathrm{~mL}$ volume into mice through the tail vein using 30 Gauge needles. Mice were maintained under anesthesia for approximately $3 \mathrm{~min}$. Following the procedure, the mice were allowed to recover on a heating pad until fully ambulatory and then returned to their home cage with immediate access to food and water.

\subsection{Multidose Experiment}

VHH triplet was used for the multidose experiment. Five mice were injected, as described above, with $0.1 \mathrm{~mL} \mathrm{VHH}$ triplet three times with 5 min intervals between each dose. Mice were maintained under anesthesia for approximately 3 min during intravenous injection and imaging and allowed to recover between injections.

\subsection{NIR Imaging Methods}

Mice were anesthetized with $60 \%$ oxygen $/ 40 \%$ medical air gas mixture with $5 \%$ isoflurane for induction of anesthesia and $1.5 \%$ isoflurane level for maintenance. Mice were imaged using the Pearl Trilogy Near-Infrared Fluorescent and Bioluminescent small animal imaging system (Licor, Lincoln, NE, USA). The specific parameters for NIR imaging were resolution $=170 \mathrm{um}$, fluorescence channel at $800 \mathrm{~nm}$ (excitation at $785 \mathrm{~nm}$ and emission at $820 \mathrm{~nm}$ ) for FNIR dye. NIR images were collected before and at time $2 \mathrm{~min}, 1 \mathrm{~h}, 2 \mathrm{~h}, 4 \mathrm{~h}$, $8 \mathrm{~h}, 1$ day, and 2 days post IV injection (Figure 9) using Pearl. After end-point imaging, mice were euthanized by transcardial perfusion using 1 X PBS with heparin under $5 \%$ isoflurane.

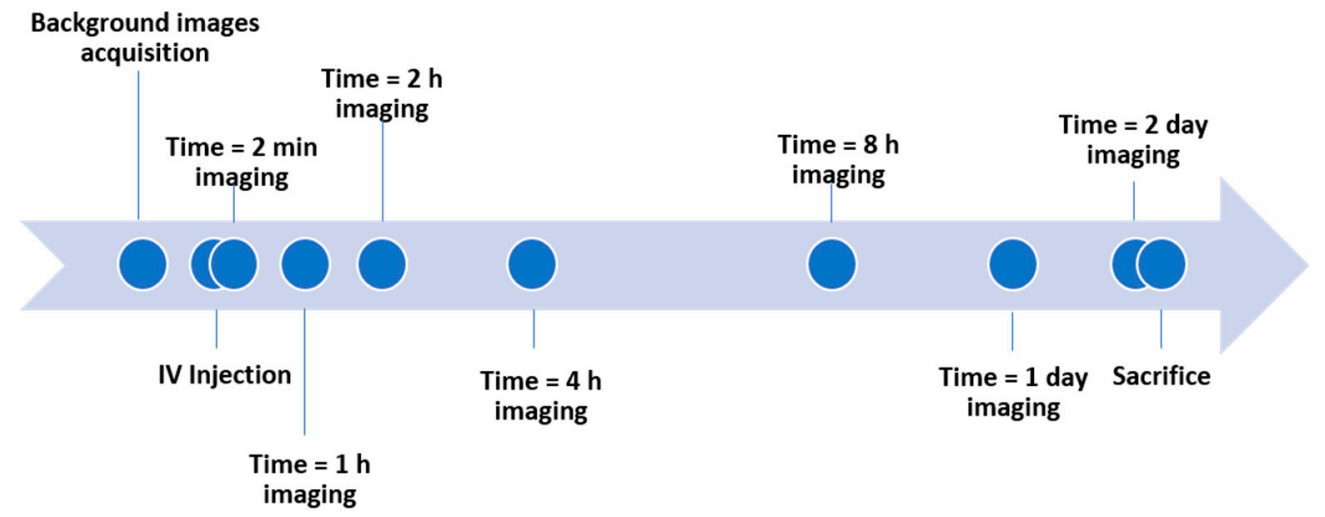

Figure 9. The experimental timeline of IV injection of VHHs and IONPs in mice. Background images were taken before injection, then NIR images were taken at $2 \mathrm{~min}, 1 \mathrm{~h}, 2 \mathrm{~h}, 4 \mathrm{~h}, 8 \mathrm{~h}, 24 \mathrm{~h}$, and $48 \mathrm{~h}$ after injection. Mice were sacrificed after imaging at $48 \mathrm{~h}$ post injection.

\subsection{Image and Data Processing}

Equally sized ROIs were manually drawn using the software Image Studio (version 5.2, Licor, Lincoln, NE, USA) from Li-Cor. Examples of ROIs are shown in Figure 1. Brain and right kidney ROIs were drawn from the prone view images while liver and front left paw 
ROIs were drawn from the supine view images. The average fluorescence intensity of each ROI was calculated and generated by Image Studio (version 5.2, Licor, Lincoln, NE, USA).

\subsection{Blood Clearance Measurement}

Twelve mice (six for each VHH) were injected with VHHs (VHH singlet, VHH triplet)

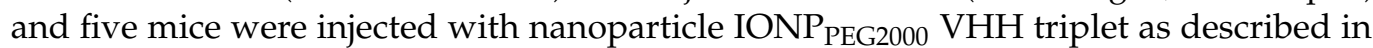
the Section 4.5. After intravenous injection, mice were sacrificed at $1 \mathrm{~min}, 5 \mathrm{~min}, 10 \mathrm{~min}$, $15 \mathrm{~min}, 30 \mathrm{~min}$, and $1 \mathrm{~h}$ for mice injected with VHHs and at $1 \mathrm{~min}, 5 \mathrm{~min}, 15 \mathrm{~min}, 30 \mathrm{~min}$, and $1 \mathrm{~h}$ for mice injected with IONP $\mathrm{PEG}_{2000} \mathrm{VHH}$ triplet. An amount of $0.1-0.2 \mathrm{~mL}$ blood was collected from the right atrium into heparin-coated $1.5 \mathrm{~mL}$ microcentrifuge tubes. The microcentrifuge tubes with blood were imaged using the Pearl system and ROIs were drawn using the Image Studio software (Figure 4).

\subsection{Mathematical Modeling}

Mathematical models were built using MATLAB (The Mathworks, Inc., Natick, MA, USA) to predict distribution and pharmacokinetics based on nanoparticle size. The mathematical models were built based on kinetic data from VHH singlet, VHH triplet, IONP PEG2000 $\mathrm{VHH}$ triplet, and IONP $\mathrm{PEG}_{2000 / 750} \mathrm{VHH}$ triplet data. Model fitting was done by minimization of the residual sum of squares across all five compartments and the blood clearance rate using the particle swarm algorithm [78,79]. $\mathrm{r}^{2}$ values were calculated to evaluate the goodness of fit. This model consists of five compartments: compartment 1 is the blood compartment, with a single bolus input and exchange of nanoparticles/VHHs with compartment 2 (kidney compartment), compartment 3 (liver compartment), and compartment 4 (brain 1 compartment). Compartment 4 also exchanges with compartment 5 (brain 2 compartment). In this model, the two main paths for clearance are the kidney and liver compartments. The kidneys and liver are the two main organs that are responsible for nanoparticle elimination [64]. The intake and clearance of nanoparticles from blood to kidneys/liver are the main characteristics that differentiate the in vivo kinetics of different nanoparticles and VHHs. The signal from spleen was not analyzed because of low signal strength. This five-compartment model was modified based on a four-compartment model with blood, liver, and kidney compartment as well but only one brain compartment. Based on AICc value [80] and model fitting, the five-compartment model was selected over the four-compartment model. Two compartments were used to better describe the nanoparticles/VHHs in vivo distribution and kinetics in the brain to guide the timing of future brain MRI studies.

\section{Conclusions}

This study investigated the PK of two VHHs and two VHH-conjugated iron oxide nanoparticles for their in vivo biodistribution and clearance in mice. A near-infrared method was established to monitor and record VHHs and VHH-IONPs kinetics in vivo. These results build a foundation for efficient understanding of VHHs and VHH-IONPs biodistribution and pharmacokinetics using near-infrared imaging.

Supplementary Materials: The following are available online at https:/ /www.mdpi.com/article/10 $.3390 /$ ijms22168695/s1.

Author Contributions: Conceptualization, S.S. and D.L.B.; Methodology, S.S. and T.J.E.; Software, S.S.; Validation, S.S.; Formal Analysis, S.S.; Investigation, S.S., D.N. and S.M.; Resources, T.J.E. and D.L.B.; Data Curation, S.S.; Writing—Original Draft Preparation, S.S.; Writing—Review \& Editing, S.S., D.L.B., T.J.E., S.M., J.H.K. and D.N.; Visualization, S.S.; Supervision, D.L.B. and T.J.E.; Project Administration, S.S.; Funding Acquisition, D.L.B. All authors have read and agreed to the published version of the manuscript.

Funding: National Institute of Neurological Disorders and Stroke (NINDS) Intramural Research Program, Uniformed Services University of the Health Sciences. 
Institutional Review Board Statement: All animal experiments were conducted under protocols approved by the National Institute of Neurological Disorders and Stroke (NINDS) / National Institute on Deafness and Other Communication Disorders (NIDCD) Animal Care and Use Committee in the National Institutes of Health (NIH) clinical center under protocol number: 1406-18.

Informed Consent Statement: Not applicable.

Data Availability Statement: The data presented in this study are available on request from the corresponding author. The data are not publicly available due to pending intellectual property disclosures.

Acknowledgments: This research was supported by the Intramural Research Program of the NIH, NINDS. Additional support was provided by the Biophysics core and Piszczerk's lab for DLS measurements. We thank Rolf Swenson and Haitao Wu from the NIH Chemistry and Synthesis Center for helping us with IONP synthesis. We thank Taegwan Hyeon for advice and support. We thank Martin J. Schnermann's lab for providing the FNIR-Tag dye for our in vivo PK study. We thank David Sept for giving us advice on modeling. We thank Alan Koretsky for providing a supportive intellectual environment. The first author would like to thank her PhD thesis committee for insightful suggestions.

Conflicts of Interest: The opinions and assertions expressed herein are those of the author(s) and do not necessarily reflect the official policy or position of the NIH, the Uniformed Services University, the Department of Defense, or other government agency.

\section{References}

1. Global Burden of Disease 2016 Neurology Collaborators. Global, regional, and national burden of neurological disorders, 1990-2016: A systematic analysis for the Global Burden of Disease Study 2016. Lancet Neurol. 2019, 18, 459-480. [CrossRef]

2. Erkkinen, M.G.; Kim, M.O.; Geschwind, M.D. Clinical Neurology and Epidemiology of the Major Neurodegenerative Diseases. Cold Spring Harb. Perspect. Biol. 2018, 10, a033118. [CrossRef] [PubMed]

3. Srinivas, N.; Maffuid, K.; Kashuba, A.D.M. Clinical Pharmacokinetics and Pharmacodynamics of Drugs in the Central Nervous System. Clin. Pharmacokinet. 2018, 57, 1059-1074. [CrossRef]

4. Sridhar, V.; Gaud, R.; Bajaj, A.; Wairkar, S. Pharmacokinetics and pharmacodynamics of intranasally administered selegiline nanoparticles with improved brain delivery in Parkinson's disease. Nanomedicine 2018, 14, 2609-2618. [CrossRef]

5. Basaia, S.; Agosta, F.; Wagner, L.; Canu, E.; Magnani, G.; Santangelo, R.; Filippi, M. Automated classification of Alzheimer's disease and mild cognitive impairment using a single MRI and deep neural networks. Neuroimage Clin. 2019, $21,101645$. [CrossRef] [PubMed]

6. Alphandéry, E. Biodistribution and targeting properties of iron oxide nanoparticles for treatments of cancer and iron anemia disease. Nanotoxicology 2019, 13, 573-596. [CrossRef]

7. Rubio, I.T.; Diaz-Botero, S.; Esgueva, A.; Rodriguez, R.; Cortadellas, T.; Cordoba, O.; Espinosa-Bravo, M. The superparamagnetic iron oxide is equivalent to the Tc99 radiotracer method for identifying the sentinel lymph node in breast cancer. Eur. J. Surg. Oncol. 2015, 41, 46-51. [CrossRef]

8. Ma, D.; Chen, J.; Luo, Y.; Wang, H.; Shi, X. Zwitterion-coated ultrasmall iron oxide nanoparticles for enhanced T1-weighted magnetic resonance imaging applications. J. Mater. Chem. B 2017, 5, 7267-7273. [CrossRef]

9. Kim, B.H.; Lee, N.; Kim, H.; An, K.; Park, Y.I.; Choi, Y.; Shin, K.; Lee, Y.; Kwon, S.G.; Na, H.B.; et al. Large-scale synthesis of uniform and extremely small-sized iron oxide nanoparticles for high-resolution T1 magnetic resonance imaging contrast agents. J. Am. Chem. Soc. 2011, 133, 12624-12631. [CrossRef] [PubMed]

10. Ta, H.T.; Li, Z.; Hagemeyer, C.E.; Cowin, G.; Zhang, S.; Palasubramaniam, J.; Alt, K.; Wang, X.; Peter, K.; Whittaker, A.K. Molecular imaging of activated platelets via antibody-targeted ultra-small iron oxide nanoparticles displaying unique dual MRI contrast. Biomaterials 2017, 134, 31-42. [CrossRef]

11. Nahrendorf, M.; Jaffer, F.A.; Kelly, K.A.; Sosnovik, D.E.; Aikawa, E.; Libby, P.; Weissleder, R. Noninvasive vascular cell adhesion molecule-1 imaging identifies inflammatory activation of cells in atherosclerosis. Circulation 2006, 114, 1504-1511. [CrossRef] [PubMed]

12. Barrow, M.; Taylor, A.; Murray, P.; Rosseinsky, M.J.; Adams, D.J. Design considerations for the synthesis of polymer coated iron oxide nanoparticles for stem cell labelling and tracking using MRI. Chem. Soc. Rev. 2015, 44, 6733-6748. [CrossRef] [PubMed]

13. Tarin, C.; Carril, M.; Martin-Ventura, J.L.; Markuerkiaga, I.; Padro, D.; Llamas-Granda, P.; Moreno, J.A.; García, I.; Genicio, N.; Plaza-Garcia, S.; et al. Targeted gold-coated iron oxide nanoparticles for CD163 detection in atherosclerosis by MRI. Sci. Rep. 2015, 5, 17135. [CrossRef] [PubMed]

14. Wei, H.; Bruns, O.T.; Kaul, M.G.; Hansen, E.C.; Barch, M.; Wiśniowska, A.; Chen, O.; Chen, Y.; Li, N.; Okada, S.; et al. Exceedingly small iron oxide nanoparticles as positive MRI contrast agents. Proc. Natl. Acad. Sci. USA 2017, 114, 2325-2330. [CrossRef]

15. Sillerud, L.O.; Solberg, N.O.; Chamberlain, R.; Orlando, R.A.; Heidrich, J.E.; Brown, D.C.; Brady, C.I.; Vander Jagt, T.A.; Garwood, M.; Vander Jagt, D.L. SPION-enhanced magnetic resonance imaging of Alzheimer's disease plaques in A $\beta$ PP/PS-1 transgenic mouse brain. J. Alzheimer's Dis. 2013, 34, 349-365. [CrossRef] 
16. Singh, N.; Jenkins, G.J.; Asadi, R.; Doak, S.H. Potential toxicity of superparamagnetic iron oxide nanoparticles (SPION). Nano Rev. 2010, 1, 5358. [CrossRef]

17. Piñero, D.J.; Connor, J.R. Iron in the Brain: An Important Contributor in Normal and Diseased States. Neuroscientist 2000, 6, 435-453. [CrossRef]

18. Ropele, S.; Langkammer, C. Iron quantification with susceptibility. NMR Biomed. 2017, 30, e3534. [CrossRef]

19. Food and Drug Administration. Feraheme (Ferumoxytol) Information. Available online: https://www.fda.gov/drugs/ postmarket-drug-safety-information-patients-and-providers/feraheme-ferumoxytol-information (accessed on 30 June 2009).

20. Toth, G.B.; Varallyay, C.G.; Horvath, A.; Bashir, M.R.; Choyke, P.L.; Daldrup-Link, H.E.; Dosa, E.; Finn, J.P.; Gahramanov, S.; Harisinghani, M.; et al. Current and potential imaging applications of ferumoxytol for magnetic resonance imaging. Kidney Int. 2017, 92, 47-66. [CrossRef]

21. Na, H.B.; Lee, I.S.; Seo, H.; Park, Y.I.; Lee, J.H.; Kim, S.W.; Hyeon, T. Versatile PEG-derivatized phosphine oxide ligands for water-dispersible metal oxide nanocrystals. Chem. Commun. 2007, 5167-5169. [CrossRef]

22. Liu, J.; Yu, M.; Ning, X.; Zhou, C.; Yang, S.; Zheng, J. PEGylation and zwitterionization: Pros and cons in the renal clearance and tumor targeting of near-IR-emitting gold nanoparticles. Angew Chem. Int. Ed. Engl. 2013, 52, 12572-12576. [CrossRef] [PubMed]

23. Hamers-Casterman, C.; Atarhouch, T.; Muyldermans, S.; Robinson, G.; Hammers, C.; Songa, E.B.; Bendahman, N.; Hammers, R. Naturally occurring antibodies devoid of light chains. Nature 1993, 363, 446-448. [CrossRef] [PubMed]

24. Muyldermans, S. Applications of Nanobodies. Annu. Rev. Anim. Biosci. 2021, 9, 401-421. [CrossRef] [PubMed]

25. Hassanzadeh-Ghassabeh, G.; Devoogdt, N.; De Pauw, P.; Vincke, C.; Muyldermans, S. Nanobodies and their potential applications. Nanomedicine 2013, 8, 1013-1026. [CrossRef] [PubMed]

26. Harmsen, M.M.; de Haard, H.J. Properties, production, and applications of camelid single-domain antibody fragments. Appl. Microbiol. Biotechnol. 2007, 77, 13-22. [CrossRef]

27. Li, T.; Vandesquille, M.; Koukouli, F.; Dudeffant, C.; Youssef, I.; Lenormand, P.; Ganneau, C.; Maskos, U.; Czech, C.; Grueninger, F.; et al. Camelid single-domain antibodies: A versatile tool for in vivo imaging of extracellular and intracellular brain targets. J. Control. Release 2016, 243, 1-10. [CrossRef]

28. Vandesquille, M.; Li, T.; Po, C.; Ganneau, C.; Lenormand, P.; Dudeffant, C.; Czech, C.; Grueninger, F.; Duyckaerts, C.; Delatour, B.; et al. Chemically-defined camelid antibody bioconjugate for the magnetic resonance imaging of Alzheimer's disease. MAbs 2017, 9, 1016-1027. [CrossRef]

29. Rincon, M.Y.; Zhou, L.; Marneffe, C.; Voytyuk, I.; Wouters, Y.; Dewilde, M.; Duqué, S.I.; Vincke, C.; Levites, Y.; Golde, T.E.; et al. AAV mediated delivery of a novel anti-BACE1 VHH reduces Abeta in an Alzheimer's disease mouse model. BioRxiv 2019. [CrossRef]

30. Esparza, T.J.; Martin, N.P.; Anderson, G.P.; Goldman, E.R.; Brody, D.L. High affinity nanobodies block SARS-CoV-2 spike receptor binding domain interaction with human angiotensin converting enzyme. Sci. Rep. 2020, 10, 22370. [CrossRef] [PubMed]

31. Huo, J.; Le Bas, A.; Ruza, R.R.; Duyvesteyn, H.M.E.; Mikolajek, H.; Malinauskas, T.; Tan, T.K.; Rijal, P.; Dumoux, M.; Ward, P.N.; et al. Neutralizing nanobodies bind SARS-CoV-2 spike RBD and block interaction with ACE2. Nat. Struct. Mol. Biol. 2020, 27, 846-854. [CrossRef]

32. Dong, J.; Huang, B.; Wang, B.; Titong, A.; Gallolu Kankanamalage, S.; Jia, Z.; Wright, M.; Parthasarathy, P.; Liu, Y. Development of humanized tri-specific nanobodies with potent neutralization for SARS-CoV-2. Sci. Rep. 2020, 10, 17806. [CrossRef] [PubMed]

33. Schoof, M.; Faust, B.; Saunders, R.A.; Sangwan, S.; Rezelj, V.; Hoppe, N.; Boone, M.; Billesbølle, C.B.; Puchades, C.; Azumaya, C.M.; et al. An ultrapotent synthetic nanobody neutralizes SARS-CoV-2 by stabilizing inactive Spike. Science 2020, 370, $1473-1479$. [CrossRef]

34. Scully, M.; Cataland, S.R.; Peyvandi, F.; Coppo, P.; Knöbl, P.; Kremer Hovinga, J.A.; Metjian, A.; de la Rubia, J.; Pavenski, K.; Callewaert, F.; et al. Caplacizumab Treatment for Acquired Thrombotic Thrombocytopenic Purpura. N. Engl. J. Med. 2019, 380, 335-346. [CrossRef] [PubMed]

35. Food and Drug Administration. FDA Approved Caplacizumab-yhdp. Available online: https://www.fda.gov/drugs/resourcesinformation-approved-drugs/fda-approved-caplacizumab-yhdp (accessed on 6 February 2019).

36. Ackaert, C.; Smiejkowska, N.; Xavier, C.; Sterckx, Y.G.J.; Denies, S.; Stijlemans, B.; Elkrim, Y.; Devoogdt, N.; Caveliers, V.; Lahoutte, T.; et al. Immunogenicity Risk Profile of Nanobodies. Front. Immunol. 2021, 12, 632687. [CrossRef]

37. Vincke, C.; Loris, R.; Saerens, D.; Martinez-Rodriguez, S.; Muyldermans, S.; Conrath, K. General strategy to humanize a camelid single-domain antibody and identification of a universal humanized nanobody scaffold. J. Biol. Chem. 2009, 284, 3273-3284. [CrossRef]

38. Knöbl, P.; Scully, M.; Cataland, S.R.; Peyvandi, F.; Coppo, P.; Kremer Hovinga, J.A.; Metjian, A.; De La Rubia, J.; Pavenski, K.; Minkue, J.; et al. Integrated Safety Results from the Phase II and Phase III Studies with Caplacizumab in Patients with Acquired Thrombotic Thrombocytopenic Purpura. Blood 2018, 132 (Suppl. S1), 3739. [CrossRef]

39. Ratain, M.J.; Plunkett, W.K., Jr. Principles of Pharmacokinetics. In Holland-Frei Cancer Medicine, 6th ed.; Kufe, D.W., Pollock, R.E., Weichselbaum, R.R., Bast, R.C., Jr., Gansler, T.S., Holland, J.F., Frei, E., III, Eds.; BC Decker: Hamilton, ON, Canada, 2003.

40. Lee, M.J.; Veiseh, O.; Bhattarai, N.; Sun, C.; Hansen, S.J.; Ditzler, S.; Knoblaugh, S.; Lee, D.; Ellenbogen, R.; Zhang, M.; et al. Rapid pharmacokinetic and biodistribution studies using cholorotoxin-conjugated iron oxide nanoparticles: A novel non-radioactive method. PLoS ONE 2010, 5, e9536. 
41. Hoshyar, N.; Gray, S.; Han, H.; Bao, G. The effect of nanoparticle size on in vivo pharmacokinetics and cellular interaction. Nanomedicine 2016, 11, 673-692. [CrossRef]

42. Kang, H.; Mintri, S.; Menon, A.V.; Lee, H.Y.; Choi, H.S.; Kim, J. Pharmacokinetics, pharmacodynamics and toxicology of theranostic nanoparticles. Nanoscale 2015, 7, 18848-18862. [CrossRef]

43. Tong, S.; Hou, S.; Zheng, Z.; Zhou, J.; Bao, G. Coating optimization of superparamagnetic iron oxide nanoparticles for high T2 relaxivity. Nano Lett. 2010, 10, 4607-4613. [CrossRef]

44. Lankveld, D.P.; Oomen, A.G.; Krystek, P.; Neigh, A.; Troost-de Jong, A.; Noorlander, C.W.; Van Eijkeren, J.C.; Geertsma, R.E.; De Jong, W.H. The kinetics of the tissue distribution of silver nanoparticles of different sizes. Biomaterials 2010, 31, 8350-8361. [CrossRef] [PubMed]

45. Xue, W.; Liu, Y.; Zhang, N.; Yao, Y.; Ma, P.; Wen, H.; Huang, S.; Luo, Y.; Fan, H. Effects of core size and PEG coating layer of iron oxide nanoparticles on the distribution and metabolism in mice. Int. J. Nanomed. 2018, 13, 5719-5731. [CrossRef]

46. Zhang, X.; Hou, Y.; Peng, C.; Wang, C.; Wang, X.; Liang, Z.; Lu, J.; Chen, B.; Dai, J.; Liu, B.; et al. Oligoethyleneoxy-Modified (99m)Tc-Labeled $\beta$-Amyloid Imaging Probes with Improved Brain Pharmacokinetics for Single-Photon Emission Computed Tomography. J. Med. Chem. 2018, 61, 1330-1339. [CrossRef]

47. Dogra, P.; Adolphi, N.L.; Wang, Z.; Lin, Y.S.; Butler, K.S.; Durfee, P.N.; Croissant, J.G.; Noureddine, A.; Coker, E.N.; Bearer, E.L.; et al. Establishing the effects of mesoporous silica nanoparticle properties on in vivo disposition using imagingbased pharmacokinetics. Nat. Commun. 2018, 9, 4551. [CrossRef] [PubMed]

48. Poulin, É.; Lebel, R.; Croteau, É.; Blanchette, M.; Tremblay, L.; Lecomte, R.; Bentourkia, M.; Lepage, M. Optimization of the reference region method for dual pharmacokinetic modeling using Gd-DTPA/MRI and (18) F-FDG/PET. Magn. Reson. Med. 2015, 73, 740-748. [CrossRef]

49. Alacam, B.; Yazici, B.; Intes, X.; Nioka, S.; Chance, B. Pharmacokinetic-rate images of indocyanine green for breast tumors using near-infrared optical methods. Phys. Med. Biol. 2008, 53, 837-859. [CrossRef] [PubMed]

50. Lortie, M.; Beanlands, R.S.B.; Yoshinaga, K.; Klein, R.; DaSilva, J.N.; de Kemp, R.A. Quantification of myocardial blood flow with 82Rb dynamic PET imaging. Eur. J. Nucl. Med. Mol. Imaging 2007, 34, 1765-1774. [CrossRef]

51. Debie, P.; Van Quathem, J.; Hansen, I.; Bala, G.; Massa, S.; Devoogdt, N.; Xavier, C.; Hernot, S. Effect of Dye and Conjugation Chemistry on the Biodistribution Profile of Near-Infrared-Labeled Nanobodies as Tracers for Image-Guided Surgery. Mol. Pharm. 2017, 14, 1145-1153. [CrossRef] [PubMed]

52. Sato, K.; Gorka, A.P.; Nagaya, T.; Michie, M.S.; Nakamura, Y.; Nani, R.R.; Coble, V.L.; Vasalatiy, O.V.; Swenson, R.E.; Choyke, P.L.; et al. Effect of charge localization on the in vivo optical imaging properties of near-infrared cyanine dye/monoclonal antibody conjugates. Mol. Biosyst. 2016, 12, 3046-3056. [CrossRef]

53. Longmire, M.; Choyke, P.L.; Kobayashi, H. Clearance properties of nano-sized particles and molecules as imaging agents: Considerations and caveats. Nanomedicine 2008, 3, 703-717. [CrossRef]

54. Haraldsson, B.; Nyström, J.; Deen, W.M. Properties of the glomerular barrier and mechanisms of proteinuria. Physiol. Rev. 2008, 88, 451-487. [CrossRef] [PubMed]

55. Lawrence, M.G.; Altenburg, M.K.; Sanford, R.; Willett, J.D.; Bleasdale, B.; Ballou, B.; Wilder, J.; Li, F.; Miner, J.H.; Berg, U.B.; et al. Permeation of macromolecules into the renal glomerular basement membrane and capture by the tubules. Proc. Natl. Acad. Sci. USA 2017, 114, 2958-2963. [CrossRef]

56. Weissleder, R.; Ntziachristos, V. Shedding light onto live molecular targets. Nat. Med. 2003, 9, 123-128. [CrossRef]

57. Xiang, H.; Cheng, J.; Ma, X.; Zhou, X.; Chruma, J.J. Near-infrared phosphorescence: Materials and applications. Chem. Soc. Rev. 2013, 42, 6128-6185. [CrossRef]

58. Maawy, A.A.; Hiroshima, Y.; Kaushal, S.; Luiken, G.A.; Hoffman, R.M.; Bouvet, M. Comparison of a chimeric anticarcinoembryonic antigen antibody conjugated with visible or near-infrared fluorescent dyes for imaging pancreatic cancer in orthotopic nude mouse models. J. Biomed. Opt. 2013, 18, 126016. [CrossRef]

59. Zaheer, A.; Lenkinski, R.E.; Mahmood, A.; Jones, A.G.; Cantley, L.C.; Frangioni, J.V. In vivo near-infrared fluorescence imaging of osteoblastic activity. Nat. Biotechnol. 2001, 19, 1148-1154. [CrossRef] [PubMed]

60. Ash, C.; Dubec, M.; Donne, K.; Bashford, T. Effect of wavelength and beam width on penetration in light-tissue interaction using computational methods. Lasers Med. Sci. 2017, 32, 1909-1918. [CrossRef]

61. Luciano, M.P.; Crooke, S.N.; Nourian, S.; Dingle, I.; Nani, R.R.; Kline, G.; Patel, N.L.; Robinson, C.M.; Difilippantonio, S.; Kalen, J.D.; et al. A Nonaggregating Heptamethine Cyanine for Building Brighter Labeled Biomolecules. ACS Chem. Biol. 2019, 14, 934-940. [CrossRef] [PubMed]

62. Gadkar, K.; Yadav, D.B.; Zuchero, J.Y.; Couch, J.A.; Kanodia, J.; Kenrick, M.K.; Atwal, J.K.; Dennis, M.S.; Prabhu, S.; Watts, R.J.; et al. Mathematical PKPD and safety model of bispecific TfR/BACE1 antibodies for the optimization of antibody uptake in brain. Eur. J. Pharm. Biopharm. 2016, 101, 53-61. [CrossRef]

63. Gobburu, J.V.; Tammara, V.; Lesko, L.; Jhee, S.S.; Sramek, J.J.; Cutler, N.R.; Yuan, R. Pharmacokinetic-pharmacodynamic modeling of rivastigmine, a cholinesterase inhibitor, in patients with Alzheimer's disease. J. Clin. Pharm. 2001, 41, 1082-1090. [CrossRef]

64. Shargel, L.; Yu, A.B.C. Applied Biopharmaceutics \& Pharmacokinetics, 7th ed.; McGraw-Hill Education/Medical: New York, NY, USA, 2012. 
65. Nagashima, R.; Levy, G.; O'Reilly, R.A. Comparative pharmacokinetics of coumarin anticoagulants. IV. Application of a threecompartmental model to the analysis of the dose-dependent kinetics of bishydroxycoumarin elimination. J. Pharm. Sci. 1968, 57, $1888-1895$. [CrossRef] [PubMed]

66. Uno, Y.; Ogawa, E.; Aiyoshi, E.; Arai, T. A Three-Compartment Pharmacokinetic Model to Predict the Interstitial Concentration of Talaporfin Sodium in the Myocardium for Photodynamic Therapy: A Method Combining Measured Fluorescence and Analysis of the Compartmental Origin of the Fluorescence. Bioengineering 2019, 6, 1. [CrossRef] [PubMed]

67. Benet, L.Z. General treatment of linear mammillary models with elimination from any compartment as used in pharmacokinetics. J. Pharm. Sci. 1972, 61, 536-541. [CrossRef]

68. Sim, H.; Bibee, K.; Wickline, S.; Sept, D. Pharmacokinetic modeling of tumor bioluminescence implicates efflux, and not influx, as the bigger hurdle in cancer drug therapy. Cancer Res. 2011, 71, 686-692. [CrossRef] [PubMed]

69. Nosrati, H.; Sefidi, N.; Sharafi, A.; Danafar, H.; Kheiri Manjili, H. Bovine Serum Albumin (BSA) coated iron oxide magnetic nanoparticles as biocompatible carriers for curcumin-anticancer drug. Bioorganic Chem. 2018, 76, 501-509. [CrossRef]

70. Li, Y.; Lin, R.; Wang, L.; Huang, J.; Wu, H.; Cheng, G.; Zhou, Z.; MacDonald, T.; Yang, L.; Mao, H. PEG-b-AGE Polymer Coated Magnetic Nanoparticle Probes with Facile Functionalization and Anti-fouling Properties for Reducing Non-specific Uptake and Improving Biomarker Targeting. J. Mater. Chem. B 2015, 3, 3591-3603. [CrossRef]

71. Liu, Z.; Dong, K.; Liu, J.; Han, X.; Ren, J.; Qu, X. Anti-biofouling polymer-decorated lutetium-based nanoparticulate contrast agents for in vivo high-resolution trimodal imaging. Small 2014, 10, 2429-2438. [CrossRef]

72. Patil, R.M.; Thorat, N.D.; Shete, P.B.; Bedge, P.A.; Gavde, S.; Joshi, M.G.; Tofail, S.A.M.; Bohara, R.A. Comprehensive cytotoxicity studies of superparamagnetic iron oxide nanoparticles. Biochem. Biophys. Rep. 2018, 13, 63-72. [CrossRef]

73. Pradhan, P.; Giri, J.; Samanta, G.; Sarma, H.D.; Mishra, K.P.; Bellare, J.; Banerjee, R.; Bahadur, D. Comparative evaluation of heating ability and biocompatibility of different ferrite-based magnetic fluids for hyperthermia application. J. Biomed. Mater. Res. B Appl. Biomater. 2007, 81, 12-22. [CrossRef]

74. Gaasch, J.A.; Lockman, P.R.; Geldenhuys, W.J.; Allen, D.D.; Van der Schyf, C.J. Brain iron toxicity: Differential responses of astrocytes, neurons, and endothelial cells. Neurochem. Res. 2007, 32, 1196-1208. [CrossRef]

75. Quan, S.; Hiniker, A.; Collet, J.F.; Bardwell, J.C. Isolation of bacteria envelope proteins. Methods Mol. Biol. 2013, 966, 359-366. [PubMed]

76. Eeftens, J.M.; van der Torre, J.; Burnham, D.R.; Dekker, C. Copper-free click chemistry for attachment of biomolecules in magnetic tweezers. BMC Biophys. 2015, 8, 9. [CrossRef]

77. Brudno, Y.; Desai, R.M.; Kwee, B.J.; Joshi, N.S.; Aizenberg, M.; Mooney, D.J. In vivo targeting through click chemistry. ChemMedChem 2015, 10, 617-620. [CrossRef] [PubMed]

78. MATLAB; Version R2019b; The MathWorks Inc.: Natick, MA, USA, 2019.

79. Marini, F.; Walczak, B. Particle swarm optimization (PSO). A tutorial. Chemom. Intell. Lab. Syst. 2015, 149, 153-165. [CrossRef]

80. Burnham, K.; Anderson, D. Multimodel Inference: Understanding AIC and BIC in Model Selection. Sociol. Methods Res. 2004, 33, 261-304. [CrossRef] 